\title{
An Accurate Mathematical Epidemiological Model (SEQIJRDS) to Recommend Public Health Interventions Related to COVID-19 in Sri Lanka.
}

Patikiri Arachchige Don Shehan Nilmantha Wijesekara ( $\nabla$ nilmantha@eie.ruh.ac.lk) University of Ruhuna

\section{Research Article}

Keywords: COVID19, Accuracy, SEQIJRDS, mortality, predictions, interventions

Posted Date: September 24th, 2021

DOl: https://doi.org/10.21203/rs.3.rs-904534/v1

License: (c) (1) This work is licensed under a Creative Commons Attribution 4.0 International License.

Read Full License 
Article

\title{
An accurate Mathematical Epidemiological Model (SEQIJRDS) to Recommend Public Health Interventions Related to COVID-19 in Sri Lanka.
}

\author{
Patikiri Arachchige Don Shehan Nilmantha Wijesekara ${ }^{1 *}$ \\ 1 Department of Electrical and Information Engineering, Faculty of Engineering, University of Ruhuna, Galle, \\ 80000, Southern Province, Sri Lanka; chatura@eie.ruh.ac.lk \\ * Correspondence: nilmantha@eie.ruh.ac.lk; Tel.: (+94710651856)
}

Version September 10, 2021 submitted to Nature Human Behaviour

\begin{abstract}
COVID-19 has been causing negative impacts on various sectors in Sri Lanka as a result of the public health interventions that government had to implement in order to reduce the spreading of the disease. Equivalent work carried out in this context is outdated and close to ideal models. This research is carried out in a crucial time which the daily deaths are rapidly increasing which arise the requirement for an accurate and practical model to predict the mortality in order to take decisions regarding public health interventions. This paper presents a mathematical epidemiological model called SEQIJRDS to predict on COVID-19. The model has been validated for the COVID 19 pandemic in Sri Lanka. The results show that the model outstands many of the state-of-the-art SEIR epidemiological models such as Imperial, IHME once properly parameterized. At the end; this work recommends public health interventions at this crucial time to save people's lives based on the predictions of the proposed model. Specifically, 3 recommendations called minimal, sub-optimal and optimal recommendations are provided for public health interventions.
\end{abstract}

Keywords: COVID19, Accuracy, SEQIJRDS, mortality, predictions, interventions

\section{Introduction}

\subsection{Background}

COVID - 19 has become the global predator of the whole world since 2019. The origin of this evil virus is China and it is believed that the COVID - 19 viruses crossed from a bat to a pangolin and finally to a human [60]. With the rapid spread occurred, Sri Lanka also became a victim of COVID 19 and these days the country faces the dreadful 3rd wave which is partly due to British and Indian variants of the virus. Literature from China found that only $20 \%$ of patients have developed the disease to a critical stage requiring ICU care while the others had less severe or mild symptoms [61]. According to [62], it is said that, $25 \%$ of the infections are asymptomatic in average. So, the actual number of infected persons is not exactly the same as the number of reported cases per day [61]. So, it is obvious that there are a lot of people who act as carriers of the disease.

The first corona virus patient who was a foreigner was found on 27th January 2020 [38]. The first ever locally infected person was found on 11th March 2020 [42]. The COVID - 19 pandemic impacted Sri Lanka as is the case in many other countries. Cases increased rapidly thereafter. The island wide curfew was implemented from mid-March to June 2020 by the government [43-46]. Only 3380 cases and 13 deaths had been reported by 30th September 2020 [38]. Then again, the country had to face the second wave of COVID - 19 and cases increased rapidly again. That time it was reported as large clusters; at a garment export factory [63] and the largest fish market in Colombo. So, it impacted Sri 
Lanka more than the first wave. However, the government could manage this with necessary steps. But now in 2021, after the Sinhala and Tamil New Year, again COVID - 19 cases are being increased. Sri Lanka is reporting about more than 4000 cases per day now (August 2021) [38]. Hospitals have enhanced capabilities; back-up plans and emergency preparedness. New hospitals for COVID patients are being built by the government. However, the system has its limitations specially in number of Intensive Care Units (ICUs) [65]. If the government cannot control the spread of infections, it will be difficult to reduce the deaths which occur as a result of that.

1.1.1. Impacts due to public health interventions

\section{Economy}

Daily wage earnings, the tourism, construction, textile industry, small and medium scale enterprises have been significantly affected due to COVID19 [66]. Because of this, the country has faced a huge economic collapse. Amid the COVID - 19 Sri Lanka's economy contracted by 3.6 percent in 2020. Sri Lankan employers have been terminated in Middle East countries and the value of Sri Lankan rupee had been depreciated with respect to USD [67]. The potential impact from COVID - 19 is unlike any other country has faced and the economy faced contraction in 2020 due to many sectors being at a standstill [68]. Country's economy mainly depends on the foreign trade and Sri Lanka can be considered as the most susceptible middle-income country due to the impact of COVID - 19 [69]. However, the clear analysis about rapid change of LKR and impact of GDP value to the economy of Sri Lanka is lacking in the research field. The economic impact to Sri Lanka is well described in [1] but it presents mainly the impact in 2019 to early 2020 period. When making public health interventions and preparing policies; a compromise has to be made between the economy and public health as the economic impact due to COVID19 preventative measures can drastically effect on the economy in South Asia which Sri Lanka is a member [24].

\section{Secondary and higher education}

Higher education in Sri Lanka is another major impacted area because of COVID - 19. Universities encounter several challenges in terms of online delivery, problems of practical test via online mode, assessments, examinations and supervision of the thesis. Survey done in the South Eastern University Sri Lanka shows that 59\% were interested in pursuing higher education online but later they lost hope in it because of poor connections, lack of devices, power outages and so on [69]. But schools and universities with advanced facilities have been able to carry out virtual classes. Online education is a new method in Sri Lankan education and it is not familiar for Sri Lankan students and teachers so that there are technology challenges and there is a tendency for increment of the mental stress of students and teachers [70].

Tourism

There were no tourist arrivals 10 months in 2020 but the country was reopened on conditional basis for tourists in 2021. However, only 19, 337 tourists have visited Sri Lanka by 2021 July which is $96.2 \%$ lesser than normal arrival [72]. The island considers that, tourism industry is one of the worst affected by the outbreak of the global pandemic [71]. CNN travel picked Sri Lanka as one of the best places to visit in 2020. Despite the tourist arrival 2021, it is clear that domestic travelers are the main reason for the third wave of Sri Lanka which is named as New Year Cluster [38].

\section{Exhaustive use of healthcare Resources}

Clinical practice guidelines for suspected and confirmed COVID cases in Sr Lanka are provided in the guideline [25]. One of the reasons for providing such a guideline is to have a policy when admitted to obtain limited resources such as ICU beds for patients. The review paper [27] presents such different 
policies used around the world when admitting to limited; but highly useful resource of ICU beds which can save the life of a critical patient.

Quality of the Environment

It seems like the only sector which is positively affected due to COVID19 is the environment. Air pollution in Sri Lanka's urban areas has decreased upto 75\% because of lockdowns which were imposed due to COVID - 19 pandemic. There is a drop in vehicular emissions in Colombo, thermal power plants and few other industrialized and urbanized localities [73].

Physical Health

Studies such as [16] provides evidence to show long term physical health impacts due to COVID19 in global level. A recent study for Sri Lanka reveals weight gain as a result of COVID19 thus increasing the chance of getting Diabetics [17]. This is further verified by [20] which shows that there is an increase of wasting and overweight among children due to COVID19 in Sri Lanka. The utmost negative impact from COVID in health terms is death. However, the death rate reported can be incorrect due to lower reporting rates and diverse factors such as age and gender according to [22].

Mental Health

There is evidence to prove that among Sri Lankan pregnant women, COVID19 had caused mental disorders [2]. Around 25\% of healthcare workers have been diagnosed as depressed according to [21]. There is further evidence for psychological distress among Sri Lankan adult population [23].

\subsubsection{Motivation}

The important fact to notice here is COVID-19 is still spreading in South Asian regions and most of the work published are in 2020. There is no research describing about spreading factors and impact on COVID19 individually for each of 7 countries or entirely the South Asian region. The paper [3] provide a review on COVID19 disease. It presents the number of patients infected, deaths of each country by early 2020 only. In other words, they are reviewed in narrow scope as evident in [4] which reviews pathophysiological on the disease. In [5]; the authors review on modern technologies for tracking COVID19. A review on COVID19 more biased to clinical aspect (diagnosis, treatment and prevention) is presented in [6,7]. Some reviews discuss on the clinical risk factors for COVID19 [8,9]. Further all of these reviews are expressing on COVID19 on global aspect. There is ample research on COVID19 published discussing on Sri Lankan aspect since what is found in global aspect can deviate based on the factors existing locally.

The paper [10] presents a review on the interventions for COVID19. But it can be argued that the work is outdated as it had been conducted in first quarter of 2020 where the vaccines were in research stage. In depth analysis of clinical interventions for COVID19 including vaccination is presented in [11]. However, there is no research determining the long-term impacts of such clinical interventions in large scale (regionally or globally). A recent review paper provides a comprehensive review on prediction models and the impact of public health interventions [12]. Research which shows the effectiveness of the non-pharmaceutical interventions on COVID19 have been studied in [13]. But they have been studied for a short period of time only.

Mahesh etc. in [18] mathematically model and evaluate numerous non-pharmaceutical interventions of Sri Lanka for a limited time period of 8 months. Similar work which mathematically model spreading using Susceptible-Exposed-Infectious-Recovered (SEIR) model [49,55] considers the spreading of the disease in the first 6 months [26]. But such work does not take into account some factors such as varieties of the COVID variants, immunization due to vaccination which had taken place recently. The time period considered in this paper is more than two years. Wijesekara etc. in [19] had used COVID19 hospital impact model to predict the number of expected infections for the navy cluster of COVID19 in Sri Lanka. 
However, a cross country study of initial growth rate of COVID19 impacted by spreading factors such as non-pharmaceutical interventions, demography, society and climate have been performed in [14]. But in this paper, additional spreading factors are taken into consideration and an updated review is presented specifically for Sri Lanka. The paper in [15] discusses the effectiveness of different lock down policies globally and derives the mobility changes based on them. This paper will discuss the how relevant is such a model to Sri Lanka.

At the moment, Sri Lanka is in the middle of a collapse in most sectors of the country. People have been suffering from this pandemic for nearly two years. Therefore, this research is also an attempt to recommend potential interventions to prevent COVID19 deaths will occur in coming months to Sri Lanka.

\subsection{Problem Statement}

Since some public health interventions related to COVID19 can drastically effect on various sectors such as economy there must be an accurate model which can predict the mortality and take decisions to balance other sectors and human lives. As reviewed, many similar existing solutions have either predicted a year ago or used simpler models so that there should be an accurate tool to predict the mortality.

\subsection{Objectives}

- To propose a mathematical epidemiological model for accurate predictions of the mortality.

- To provide recommendations for public health interventions by discussing the impacts of predicted results under different interventions.

\section{Methodology}

\subsubsection{Eligibility Criteria}

Any acceptable COVID19 data source related to Sri Lanka up to the date of August $31^{\text {st }}$ of 2021 was selected.

\subsection{Data collection process}

\subsection{1. collection methods}

The data was collected into a Microsoft Excel Spreadsheet file. No automation tool was used for importing the data into the Excel sheet. Raw Data from the reports were manually inserted.

\subsubsection{Data items}

Assumptions and estimations have been made regarding missing/erroneous/unclear information. In cases which there were such data, the assumptions or estimations have been stated at the spot of analysis or description.

\subsubsection{Study risk of bias assessment}

We minimize the bias that occurs from data of different sample sizes collected from different sources for analysis as a data pre-processing procedure. For example; we model the parameter mobility $(\mu)$ as a normalized parameter in our design which will be explained later.

\subsubsection{Effect measures}

Where appropriate, we use the standardized mean difference as an effect measure. 


\subsubsection{Certainty assessment}

- We specify a 95\% confidence limit in parameter extraction using the historical data. We do not specify a Confidence Interval (CI) for the predictions since we consider different scenarios within the confidence limit for analysis (Either at limits or within the limits). When we predict the outcomes, we specify at which point of the Confidence Interval these predictions are done for. Ex: whether at the extreme ends or for the average case etc.

\subsection{Epidemiology Model}

As mentioned in the review; the work in [26] which uses a Susceptible-Exposed-Infectious-Recovered (SEIR) model [49] considering the spreading of the disease in the first 6 months does not take into account some factors such as varieties of the COVID variants, immunization due to vaccination, age distribution of the population etc. It assumes that all recovered patients have $100 \%$ immunity for the disease and are non-susceptible which is ideal since a patient recovered from a variety with low viral load can get infected again with a variety with a high viral load. So, we do not employ the SEIR model here. We consider the practical situation where from the isolated (hospitalized) group; only a fraction $\left(P_{J}\right)$ enter the removed group either by dying or developing total immunity by recovering from the illness. Similarly a fraction $P_{I}$ enter the removed group and $\left(1-P_{I}\right)$ enter the susceptible group from the Infected Population $(I) .\left(P_{S}\right)$ is the fraction of susceptible population who develop full immunity to the infection with vaccination.

Therefore, for this study we deviate from such ideal assumptions which can cause inaccuracies in the predicted outcomes and use the Epidemic Management model which is highly complying with the current interventions practiced in Sri Lanka. Since nearly 50\% of the population of Sri Lanka is vaccinated with both doses at the time of writing [38], a vaccination class which is partially immune to the disease must be considered for modeling as highlighted in [49].

So, with above justifications, we introduce a modified model known as Susceptible, Exposed, Quarantined, Infected, Hospitalized, Recovered, Dead, Susceptible (SEQIJRDS) model which is formed by using SEIS model, SEIR model and SEQIJR model given in [49] and by introducing a new class known as Dead. We introduce this dead class since the rate and number of deaths are important parameters when taking decisions about the health interventions so that it is identified separately without identifying it in the "Removed" class as in [49] which includes both dead and fully recovered patients in the same removed class. It should be noted that we use $\mathbf{R}$ class to identify fully immunized population against the infection. These are compartment models which the population (N) under consideration is divided into compartments and there is a rate of moving from one compartment into another. The compartments and the associated movements are given in the Figure 1.

As shown in Figure 1, following points can be observed. The bold points are novel parameters introduced in this model.

- $\beta$ is the contact rate factor of the susceptible population.

- $\eta$ is the final dose vaccination rate of the susceptible population 3 weeks before the present date

- Exposed members are quarantined at a rate of $\gamma_{1}$

- We introduce the parameter $0<\lambda$ to represent the infection capabilities across different variants of the disease. The variant with highest viral load will have a value of 1

- Exposed members who are not quarantined are infected at a rate of $k_{1}$ for the base/original Infectant. $k_{1} * \lambda$ is the effective infection rate adjusted with the effect of COVID19 variants.

- Infectives are diagnosed at a proportional rate $\gamma_{2}$ per unit time and isolated.

- quarantined members are monitored and when they develop symptoms; they are removed from quarantine to isolation at rate $k_{2}$

- Exposing of a susceptible population takes place from the infected population (I), factor of $\epsilon_{Q}$ due to imperfect quarantine out of Quarantine population (Q), factor of $\epsilon_{J}$ due to imperfect isolation out of isolation population $(J)$, factor of $\epsilon_{E}$ out of the exposed population (E) 


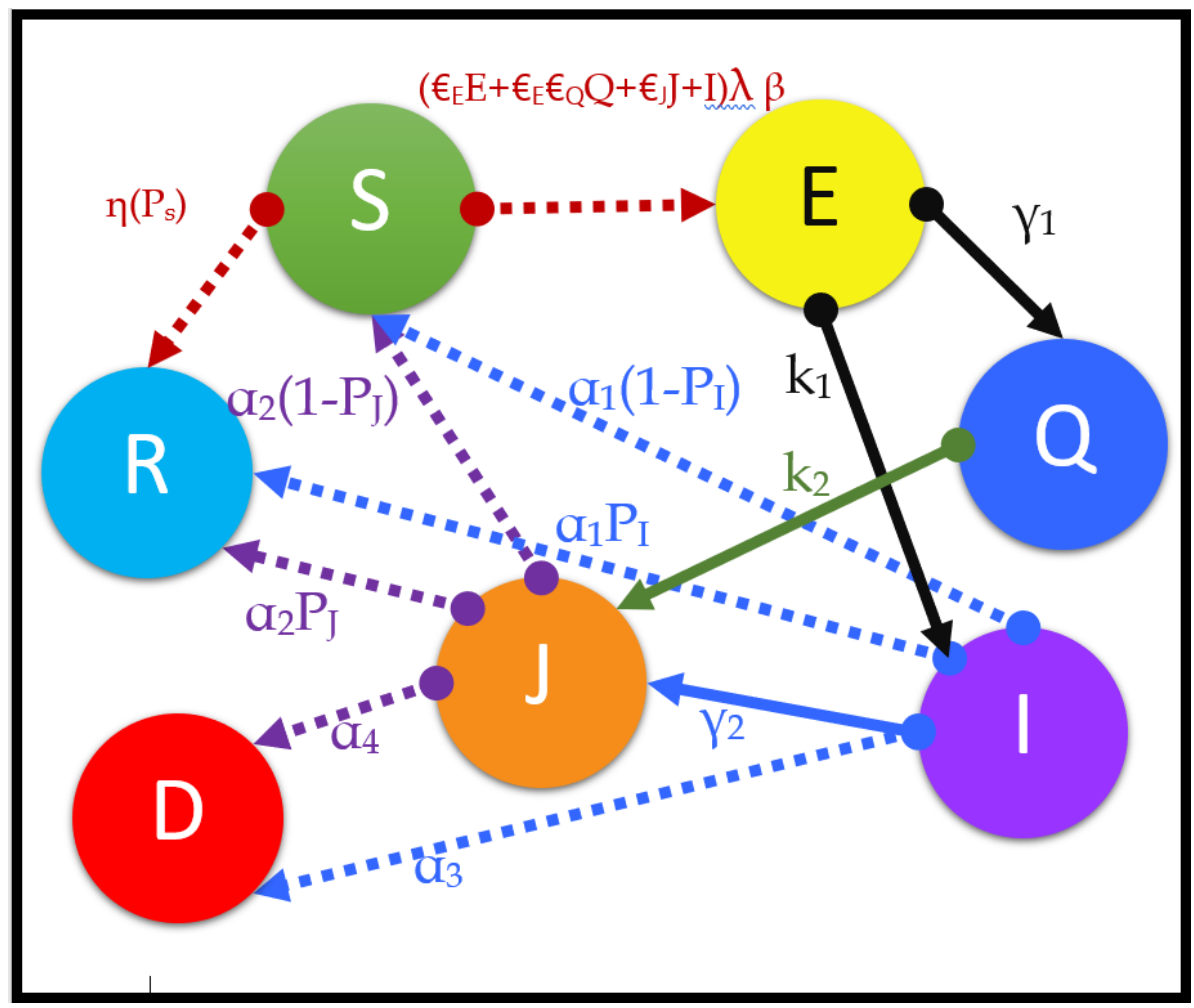

Figure 1. Proposed SEQIJRDS Model

- $\alpha_{1}$ is the number of people recovering per unit time from non-hospitalized infectants

- $\alpha_{2}$ is the number of people recovering per unit time from hospitalized infectants

- $\alpha_{3}$ is the death rate of non-hospitalized infectants

- $\alpha_{4}$ is the death rate of hospitalized infectants

- $P_{S}$ is the probability of developing full immunity by vaccination

- $P_{I}$ is the probability of recovering with full immunity from non-hospitalized infectants

- $P_{J}$ is the probability of recovering with full immunity from hospitalized infectants

Differential equations can be written as follows by considering the rate of change of population at each of the compartments.

$$
\begin{gathered}
\frac{d S}{d t}=-\left(\epsilon_{E} E+\epsilon_{E} \epsilon_{Q} Q+\epsilon_{J} J+I\right) \lambda \beta S-\eta S P_{S}+\alpha_{1}\left(1-P_{I}\right) I+\alpha_{2}\left(1-P_{J}\right) J \\
\frac{d E}{d t}=\left(\epsilon_{E} E+\epsilon_{E} \epsilon_{Q} Q+\epsilon_{J} J+I\right) \lambda \beta S-\left(k_{1}+\gamma_{1}\right) E \\
\frac{d Q}{d t}=\left(\gamma_{1}\right) E-k_{2} Q \\
\frac{d I}{d t}=k_{1} E-\left(\gamma_{2}+\alpha_{1} P_{I}+\alpha_{3}+\alpha_{1}\left(1-P_{I}\right)\right) I \\
=\lambda k_{1} E-\left(\gamma_{2}+\alpha_{3}+\alpha_{1}\right) I
\end{gathered}
$$




$$
\begin{gathered}
\frac{d J}{d t}=\gamma_{2} I+k_{2} Q-\left(\alpha_{2} P_{J}+\alpha_{4}+\alpha_{2}\left(1-P_{J}\right)\right) J \\
=\gamma_{2} I+k_{2} Q-\left(\alpha_{4}+\alpha_{2}\right) J
\end{gathered}
$$

The model without control measures will reduce to simple SEIR model with $k_{1}, \alpha_{1}, \beta$ not equal to zero and all other rates and fractions in above equations will become zero.

Initially at time $t=0$ (just before the disease is going to infect for the first time for already exposed population) all $Q=I=J=R=D=0$ and $S+R=N_{0}$. At infinite time (Long time after first infection), we do not assume that the population is not fully immune to the disease which is practical which can occur due to mutated variants of the COVID19. So, $S, Q, I, J, E, D, R$ is not equal to zero after infinite time which is different compared to [49]. We can use these initial conditions and knowledge of rates and probabilities identified by using historical data to predict the number of infections, number of people under isolation (Hospitals) which will be very useful in deciding the public health interventions and hospital resource use management.

Unlike the procedure given in [49], during the pandemic, the probabilities and rates specified in Equations 1-7 are not constants. So, we model them as variables of time and derive the equations for such variables based on the historical data observations of the pandemic and logical reasoning.

We solve the system of First order differential equations using MATLAB software tool. The statistical analysis of the historical data was performed using Microsoft Excel to deduce the rates and probabilities.

Each of the variables can be modelled as given in the following subsections.

\subsubsection{The Contact probability $(\beta)$}

The contact probability depends on the normalized average mobility $(\mu)$ of the population and expose preventative measures $(M)$ such as mask use, social distancing, hand sanitizing. Both $\mu$ and $M$ depend on the government policies and behavior adhering to policies of the general public. We model $\beta$ as given by the Equation 8 .

$$
\beta=\mu * M * \beta_{0}
$$

Here, $\mathrm{M}$ is a normalized parameter which has a value of 0 under highest possible exposure prevention measures and has a value of 1 at no preventative measures. $M=0.05$ for the universal mask use case which assumes that all susceptible population wear a mask which prevents contacting with the disease by a probability of 0.95 . We define $b e t a_{0}$ as the base contact probability which can change over time. We derive $b e t a_{0}$ using curve fitting for historical data so that this becomes a learned parameter.

\subsubsection{Contact Tracing and Quarantine rate $-\gamma_{1}$}

The quarantine rate is an important parameter which can control the spreading of the disease. But the problem is that there is no data to obtain this mainly because there has been double counting (Not 
Table 1. Summary table of travel restrictions

\begin{tabular}{|c|c|c|}
\hline Scenario & Start Date & End Date \\
\hline Islandwide full lockdown & 20-March-2020 & 23-March-2020 \\
\hline Islandwide full lockdown & 23-March-2020 & 19-April-2020 \\
\hline Islandwide full lockdown & 23-April-2020 & 11-May-2020 \\
\hline Islandwide full lockdown & 23-May-2020 & 26-May-2020 \\
\hline Restric travel in selected high risk areas & 4-October-2020 & 18-October-2020 \\
\hline Full lockdown in western province & 18-October-2020 & 05-November-2020 \\
\hline Restrict travel in selected high risk areas & 05-November-2020 & 10-May-2021 \\
\hline Restrict inter-provincial travel & 10-May-2021 & 21-May-2021 \\
\hline Islandwide full lockdown & 21-May-2021 & 21-June-2021 \\
\hline Restrict inter-provincial travel & 21-June-2021 & 01-August-2021 \\
\hline
\end{tabular}

deducting after being hospitalized from the quarantined population) in reports of the epidemiology unit of Sri Lanka [38]. Therefore, this parameter had to be estimated using the historical data and mobility. We modelled this parameter as a function of mobility also since mobility reduction enhances quarantine and vice versa. The equation is as shown in Equation 9

$$
\gamma_{1}=(1-\mu) * g a m m a_{0}
$$

where $g a m m a_{0}$ is the base quarantine rate. We obtained the value for $g a m m_{0}$ by curve fitting for the historical data since the data is erroneous.

\subsubsection{Mobility}

The mobility data of Sri Lankans were collected from Google [39]. The travel restriction periods can be summarized as in Table 1 which dates obtained from [43-48].

The mobility of Sri Lankans during the pandemic period is shown in Figure 2. Here, data was collected from Google mobility reports [39] and plotted.

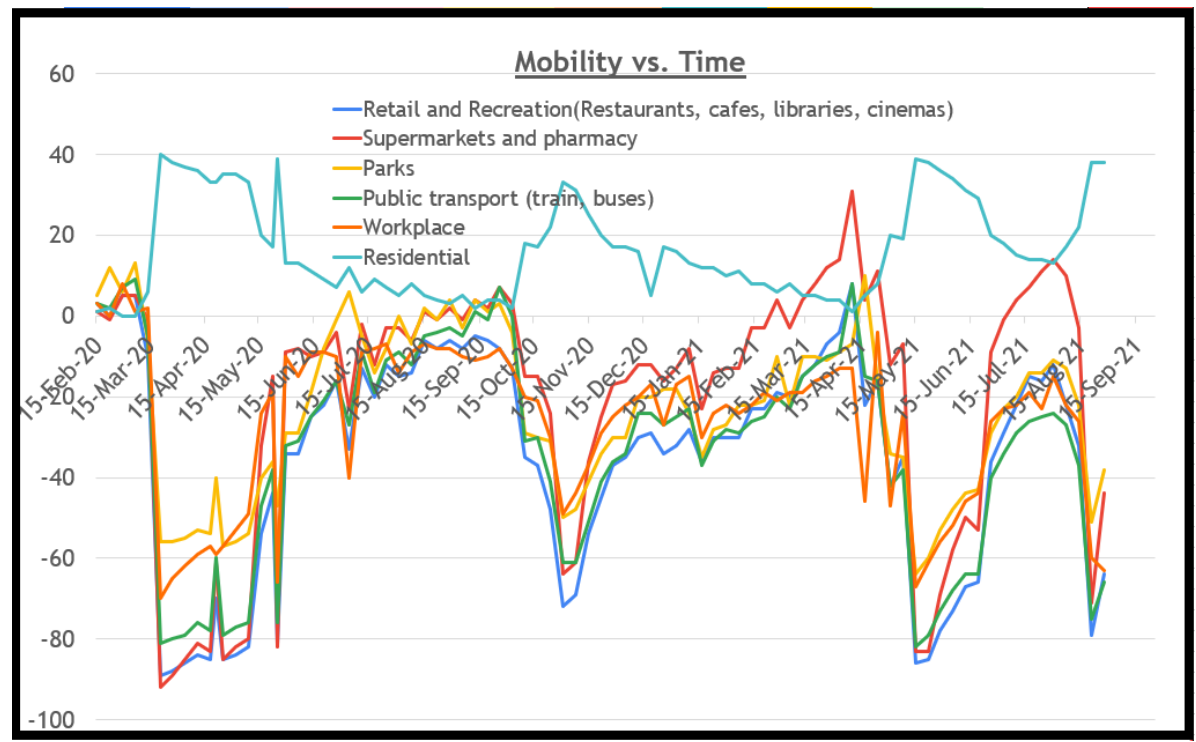

Figure 2. Instantaneous Mobility under different categories

In Figure 2, it can be observed a low cross correlation between all non-residential data and residential data showing that travel restrictions have effectively reduced non-residential mobility 
but, has increased residential mobility. However, as residential groups have very small size groups typically 2-4 people, the impact on spreading the disease is low from residential groups.

So, to observe the mobility; we calculate the average mobility across 6 different sections given in Figure 2 and use min-max normalization to map into a variable between 0 to 1 . The result is as seen in Figure 3.

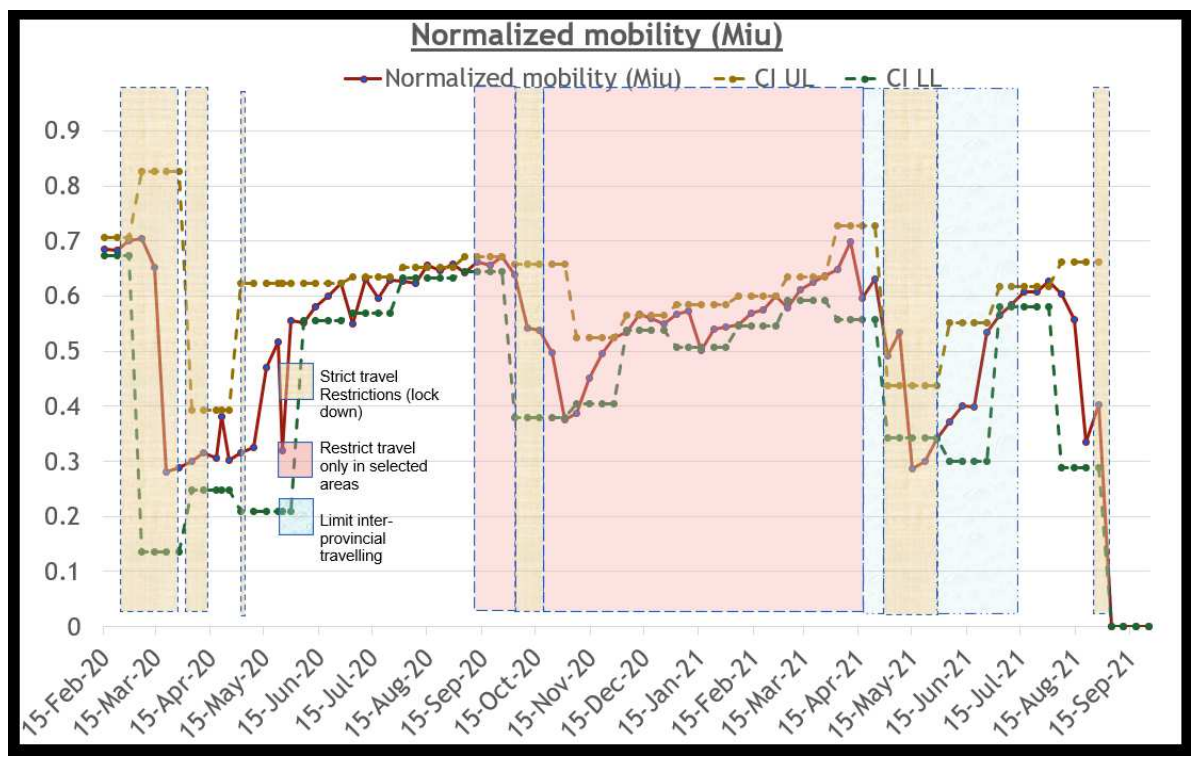

Figure 3. Normalized Mobility Vs. time during the COVID 19 Pandemic

When observing the result, it is very clear that during the full lockdown periods, the average mobility has been low at an average of 0.34 and a $95 \%$ confidence interval of $(0.23-0.45)$. The average mobility during the pandemic when there is no travel restriction is 0.67 with a low standard deviation of 0.0004 . So, the observation is that the average mobility can be halved by using total lockdowns in Sri Lanka. If the binary discrete event: lockdown state is represented by $L$ then the mobility is given by Equation 10 as,

$$
\begin{array}{r}
\mu=0.34 * L-(L-1) 0.67 \\
=-0.33 * L+0.67
\end{array}
$$

Therefore, we can obtain an approximate value for $\beta$ using the above observation. The value of $\beta$ is very critical in the pandemic since it will govern all other rates. From Equation 8,

$$
\beta=(-0.33 * L+0.67) * M * \text { beta }_{0}
$$

considering the discrete event Lockdown $\mathrm{L}$. This equation can be used to measure the effectiveness of lockdown on the spreading of the pandemic. Otherwise, the instantaneous normalized mobility should be used in solving the Equation 8

\subsubsection{Vaccination Rate - $\eta$}

The population of Sri Lanka is 21,514,267 according to [36]. Vaccine is for all humans aged greater than 18. Population percentage of such people is around $67 \%$ [35]. Therefore, eligible population for vaccination is around 14.4 million. In order for a Vaccine to get accepted by the WHO; it needs to have an efficacy of at least 50\% [50]. Therefore, all COVID19 vaccines have an efficacy of 50\%. But, in order to achieve this efficacy, three weeks should elapse after taking the final dose of the vaccination [50]. Therefore, the value of $P_{S}$ can be taken as 0.5 . Next parameter is finding out the final dose vaccination rate $(\eta) 3$ weeks before the present date. Vaccination data was collected from the epidemiology unit of Sri Lanka. Figure 4 shows the cumulative vaccination values at the end of each month. 


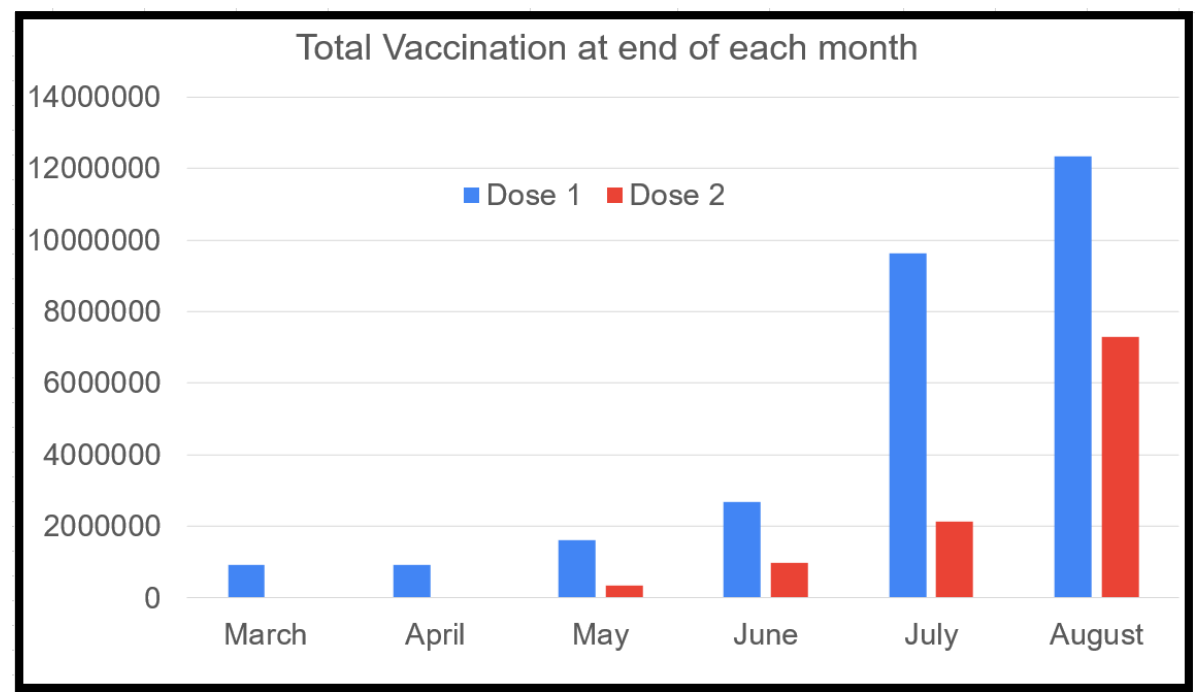

Figure 4. Total vaccination by the end of each month

As evident from Figure 4, 86\% of the eligible population has been given the first dose and $51 \%$ of the eligible population has been given the second dose by the end of August 2021. The vaccination process has been started in March and only a few has been vaccinated in April due to the Sinhala and Hindu new year vacation period.

Figure 5 shows the variation of average vaccination per of each month for each type of the vaccine.

As seen from Figure 5, the Astrazenaca vaccinate has been mainly given at the start of the vaccination program. However, at the beginning of April Sinopharm vaccination has been started and then continued as the dominant vaccine with the highest rate of vaccination.

Now, let us determine the parameter $\eta$. For this, we need to shift the time axis of vaccination by 3 weeks for the second dose for all the vaccines. Since we do calculations at the end of each month, for convenience, we shift the time axis by 1 month not 3 weeks. The graph obtained in this manner is given in Figure 6

$\eta$ should be found graphically using the graph in Figure 6 which has a non-linear variation. This $\eta$ values will be used in solving the differential equations in the proposed SEQIJRDS model.

2.2.5. Variants and clusters of COVID - 19 found in Sri Lankan society

Currently, there are six main variants found in Sri Lankan society [28] as shown in the Table 2.

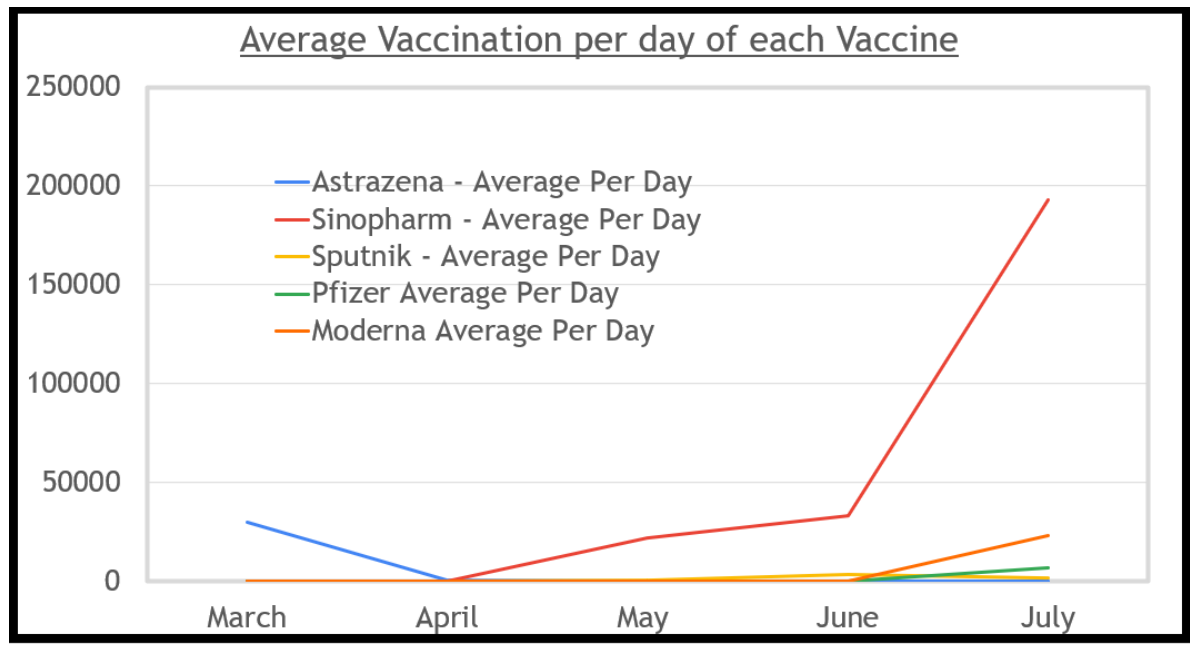

Figure 5. average vaccination per of each month for each type of the vaccine 


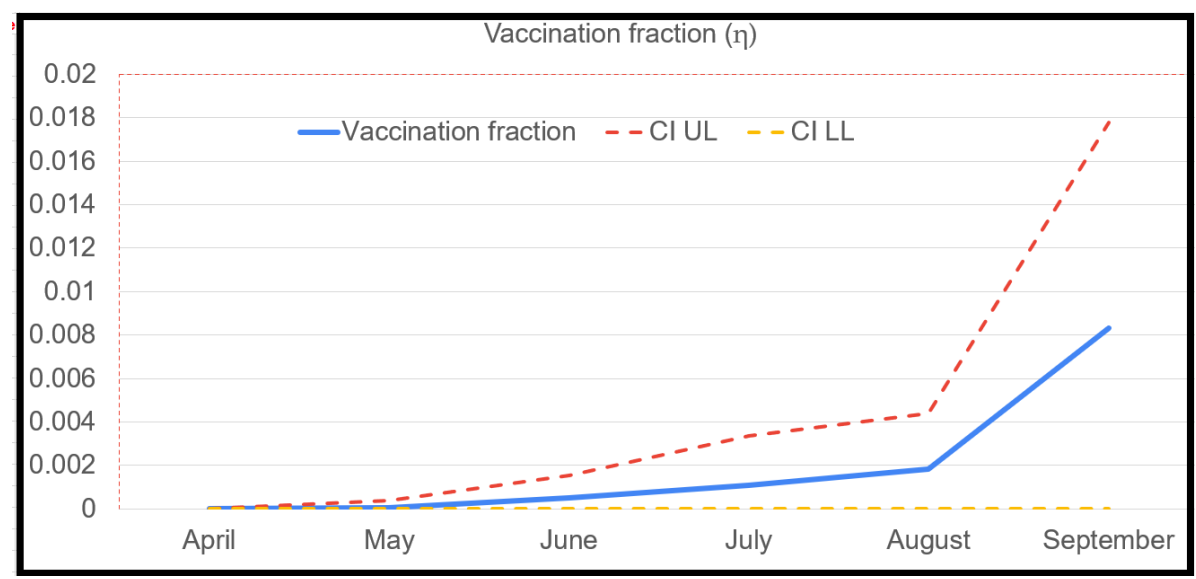

Figure 6. Effective vaccination rate of the second dose with Confidence Limits

Table 2. Summary table of COVID19 variants found in Sri Lanka

\begin{tabular}{|c|c|c|}
\hline Variant Name & Earliest date of Detection & transmissibility $(\boldsymbol{\lambda})$ \\
\hline B.1.411 (Sri lankan variant) & 02-April-2020 [29] & $1.02[52]$ \\
\hline B.1.1.7 (Alpha - UK variant) & 02-January-2021 [33] & $1.29[51]$ \\
\hline B.1.351 (Beta-south african variant) & 03-March-2021 [34] & $1.25[51]$ \\
\hline B.1.428 (Denmark Variant) & 03-March-2021[32] & unknown \\
\hline B.1.617.2 (Delta - Indian Variant) & 07-April-2021 [30] & $1.97[51]$ \\
\hline B.1.525 (Nigerian variant) & 28-April-2021 [31] & $1.29[51]$ \\
\hline SA 222V, SA 701S, SA 1078S & 17-August-2021 [40] & unknown \\
\hline
\end{tabular}

We consider the highest $\lambda$ value of the varieties of COVID19 found at a particular time in Sri Lanka in our calculation. That is $\lambda=1.02$ prior to 02-January of 2021, $\lambda=1.29$ from 02-January-2021 to 07-April-2021 and after 07-April-2021; $\lambda=1.97$

\subsubsection{Daily Hospitalizations}

Figure 7 shows the average number of daily hospitalizations for each month. The hospitalization sources are quarantine centers $(Q)$ and non-isolated infectants from the society (I). This gives a value for $k_{2} * Q+\gamma_{2} * I$

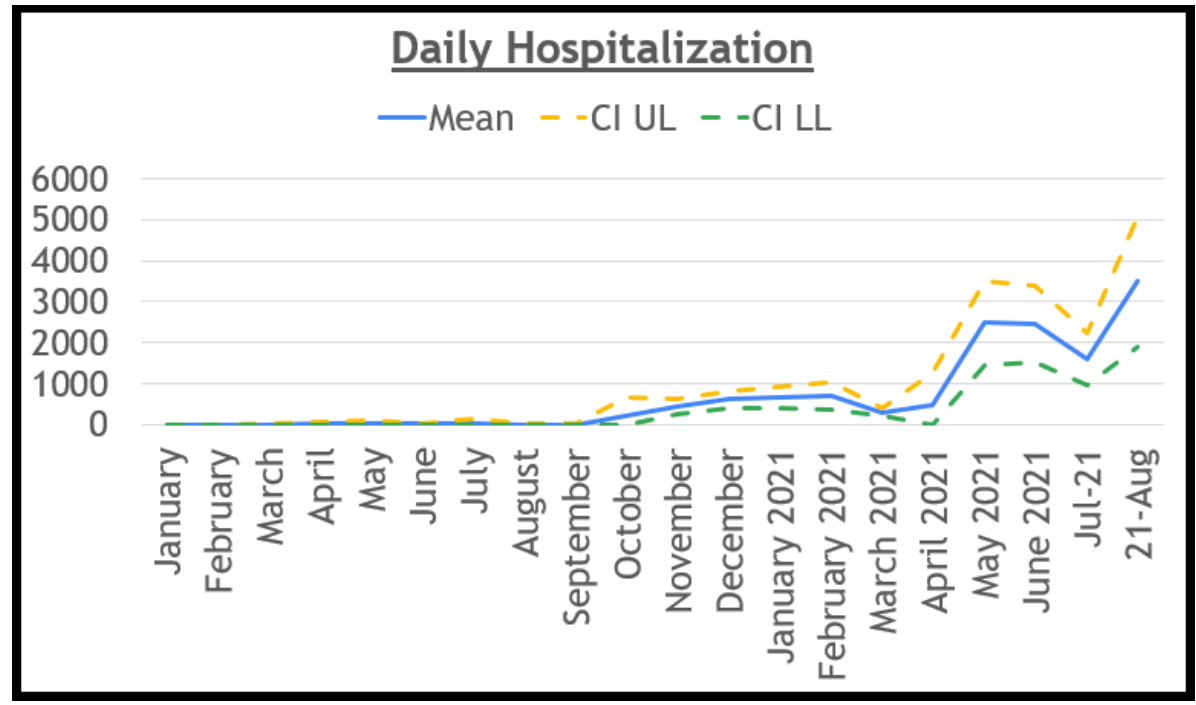

Figure 7. Number of Patients hospitalized per day for each month during the pandemic 
2.2.7. Total patients in Hospitals - $\mathrm{H}$

Figure 8 shows the total infectants residing in the hospitals at the end of each month.

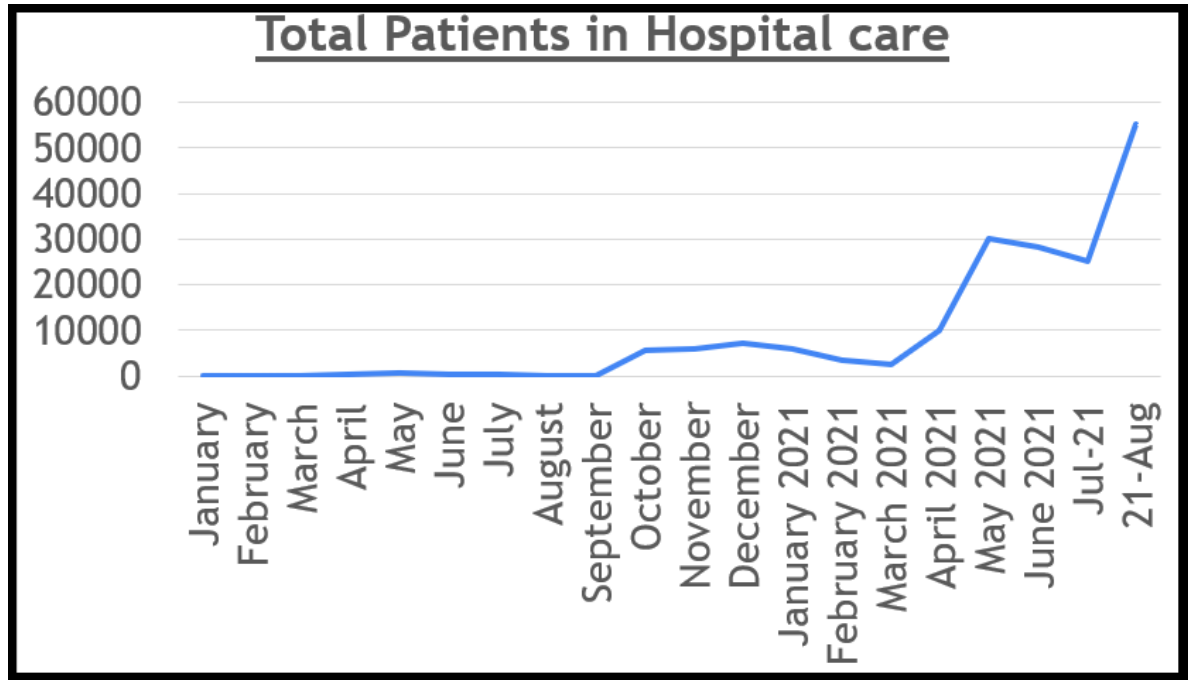

Figure 8. Number of Patients in Hospitals for each month during the pandemic

Graph in Figure 8 provides the value for the class "H" of the epidemic model. The values of this graph can be used as initial conditions for future predictions or to validate the predictions. The gradient of this graph gives the hospitalization rate.

\subsubsection{Hospitalized Recovery Fraction $-\alpha_{2}$}

What is given by the epidemiology unit as recovery is the number of patients recovering in the hospitals. That is an ideal recovery where $\eta=0, P_{I}=1, P_{I}=1$ where the patients recovered will go only to the removed class R. So, the real daily recovered patients with $100 \%$ immunity against the disease will be different to the one reported. But we can approximate $\alpha_{2}$ using the

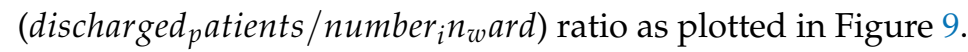

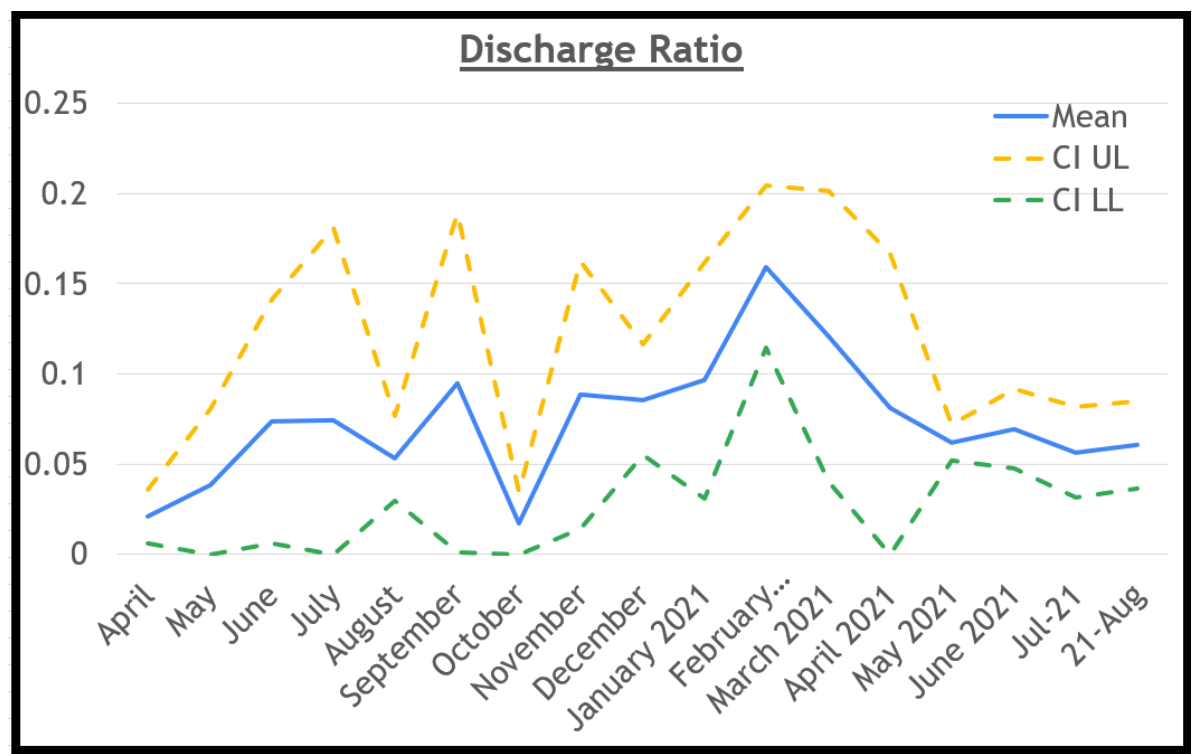

Figure 9. Recovery fraction variation during the pandemic. 
It should be noted that the fraction of COVID19 victims who recover without being diagnosed as infectants is not reported and hence unknown. So, the value of $\alpha_{1}$ has to be learned using curve fitting for historical data.

\subsubsection{Death Fraction $-\alpha_{4}$}

From data, we calculate the ratio between the number of deaths and infected patients for hospitalized population as shown in Figure 10. The value at each point of the graph will be used as initial conditions when solving the system of differential equations.

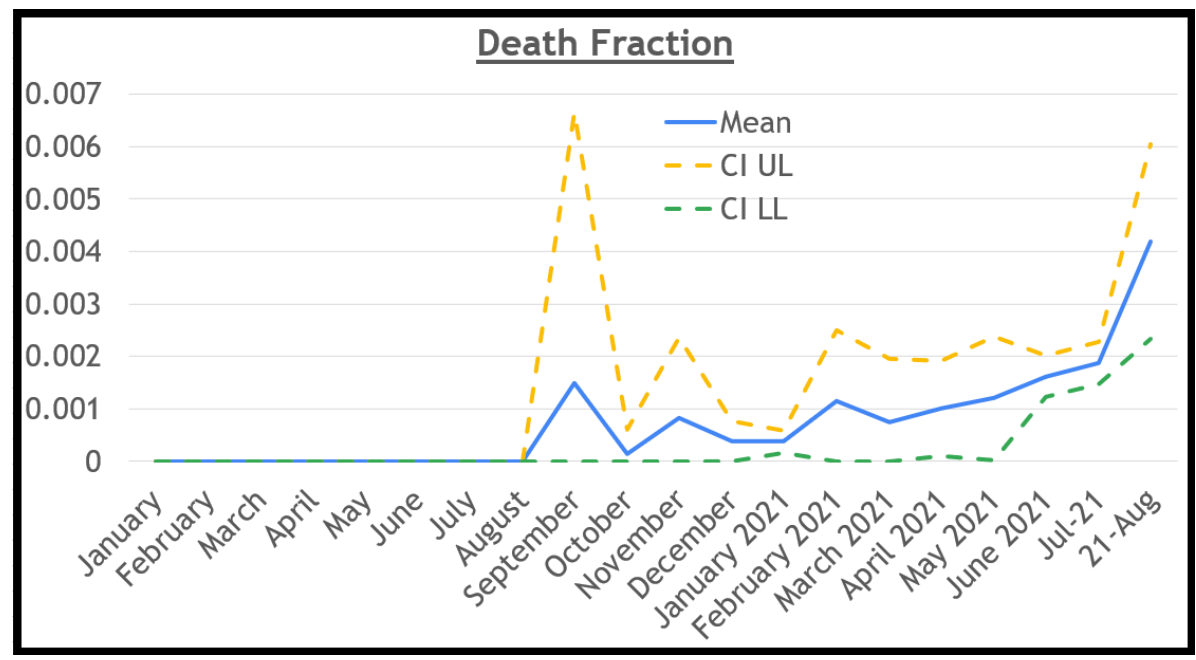

Figure 10. Death fraction for each month during the pandemic

The fractional rate of deaths from infected people in the society $\left(\alpha_{3}\right)$ is unknown and typically will not be reported as COVID 19 death. In this paper we set $\left(\alpha_{3}=\alpha_{4}\right)$ which is a fair assumption since both non-isolated infectants and isolated infectants are evolved from the same exposed population.

\subsubsection{Adjustment to death under-reporting}

According to World Health Organization, it is estimated that only 10\% to $98 \%$ of actual COVID 19 deaths are reported in countries. It is obvious that deaths from hospitalized COVID19 cases who die are reported 100\% since Sri Lanka reports COVID19 deaths accurately for the hospitalized patients. Non-reporting occurs from the deaths from the class I in the epidemiology model. Since the deaths from class I and class $\mathrm{H}$ are equally likely; in average $50 \%$ of deaths can go under-reported. With this argument, we double the reported deaths before feeding as an initial condition for the epidemiological model.

Figure 11 shows the under-reporting adjusted variation of the death class at the end of each month during the pandemic. 


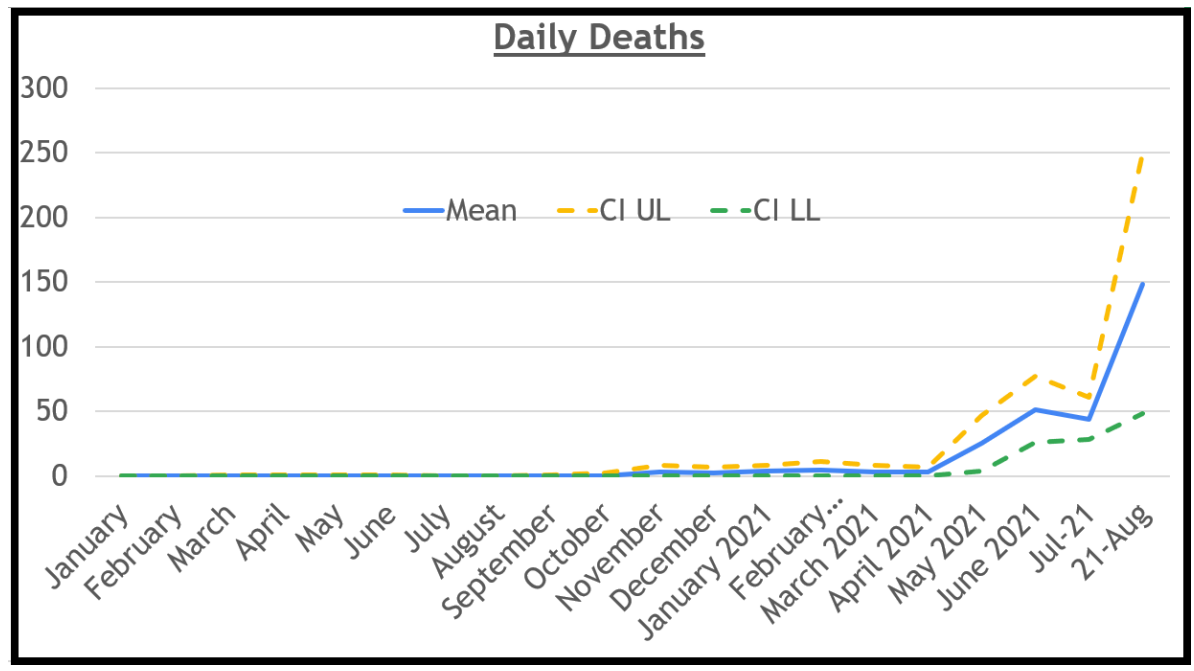

Figure 11. Average Number of daily deaths for each month during the pandemic

\section{Results}

\subsection{Model simulation for Sri Lanka}

We simulate the model in MATLAB R2021a. We set the Model parameters with values we derived in the methodology. Figure 12a and 12b show the variation of the population of each class with time. Here, last 3 months have been predictions under the following interventions.

- No lock-down for the last 3 months

- vaccination is continued

- No changes in Quarantine measures or any other preventative measures

- Universal mask use case 


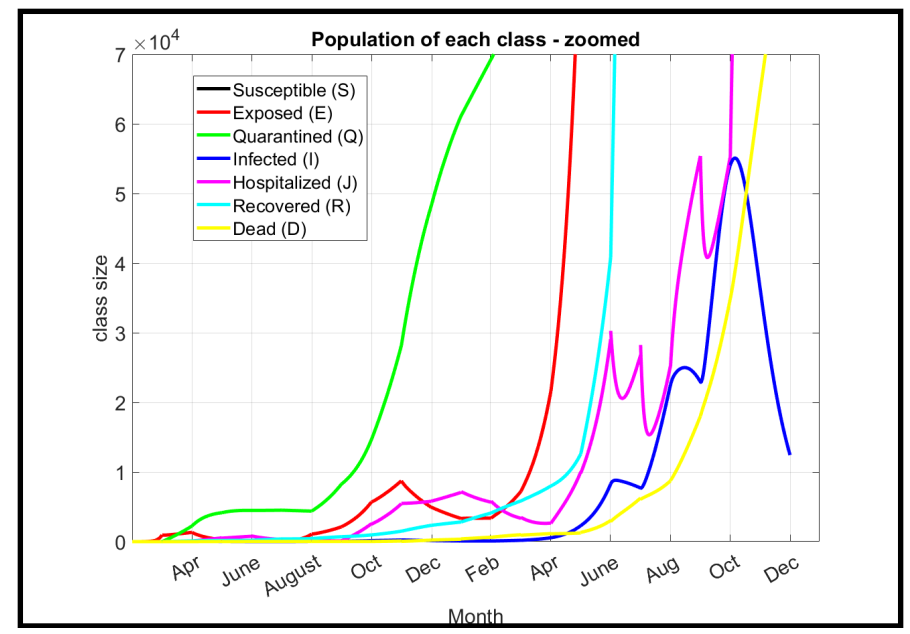

(a) Population sizes for proposed SEQIJRDS model zoomed in y axis

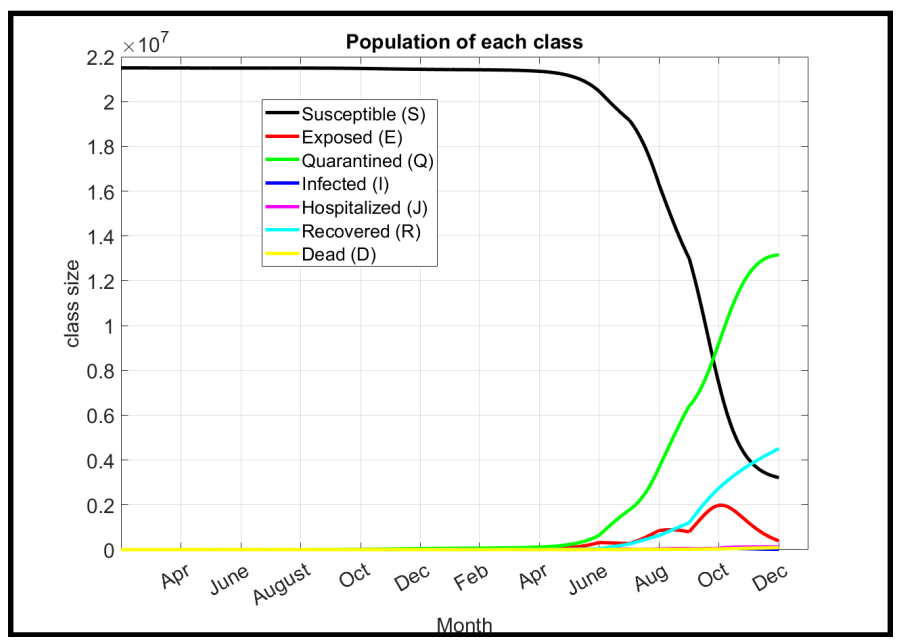

(b) Population sizes for proposed SEQIJRDS model without zooming in y axis

Figure 12. Simulation result of the whole pandemic with predictions for Sri Lanka

It is clear that according to predictions from the proposed SEQIJRDS model that the disease will have a peak of infectants by early October and it will fade away and the number of infectants in the society will reduce by the beginning of December. It is highly unlikely that another wave of COVID 19 to arise after that as the susceptible population after December will be at a low value around 3 million unless a new COVID variant which can infect ' $R$ ' class who have developed $100 \%$ immunity to previous variants hit Sri Lanka.

\subsection{Validation of the proposed model}

We compare proposed model against historical data for the months of July and August of 2021 which had passed at the time of writing in order to validate the model. We use the Mean Absolute Percent Error (MAPE) in order to validate the model. The equation for MAPE is given in Equation 11. Here, it should be noted that learned parameters up to the Month of June will be used in generating the predictions. The parameters learned in July and August are not used as they are generated as predictions. 
Table 3. Table of Mean Absolute Percent Error comparison between the proposed SEQIJRDS method and other prediction models

\begin{tabular}{|c|c|c|c|c|}
\hline Number of Weeks & Proposed & IHME[58] & SIKJalpha[57] & Imperial[59] \\
\hline 2 & 0.37 & 2 & 0 & 3 \\
\hline 4 & 1.64 & 4 & 1 & 12 \\
\hline 6 & 5.69 & 7 & 2 & 20 \\
\hline 8 & 8.82 & 12 & 3 & 21 \\
\hline
\end{tabular}

$$
M A P E=100 * \frac{1}{n}\left(\sum_{1}^{n} \bmod \left(\frac{A_{t}-P_{t}}{A_{t}}\right)\right)
$$

where $A_{t}$ Absolute value of the Prediction $P_{t}$ at time t. $\mathrm{n}$ is the number of predicted values. Figure 13 shows the proposed model's predictions for the mortality due to COVID 19 and actual mortality which occurred. Here, it should be noted that as mentioned before; $50 \%$ under-reporting situation is considered.

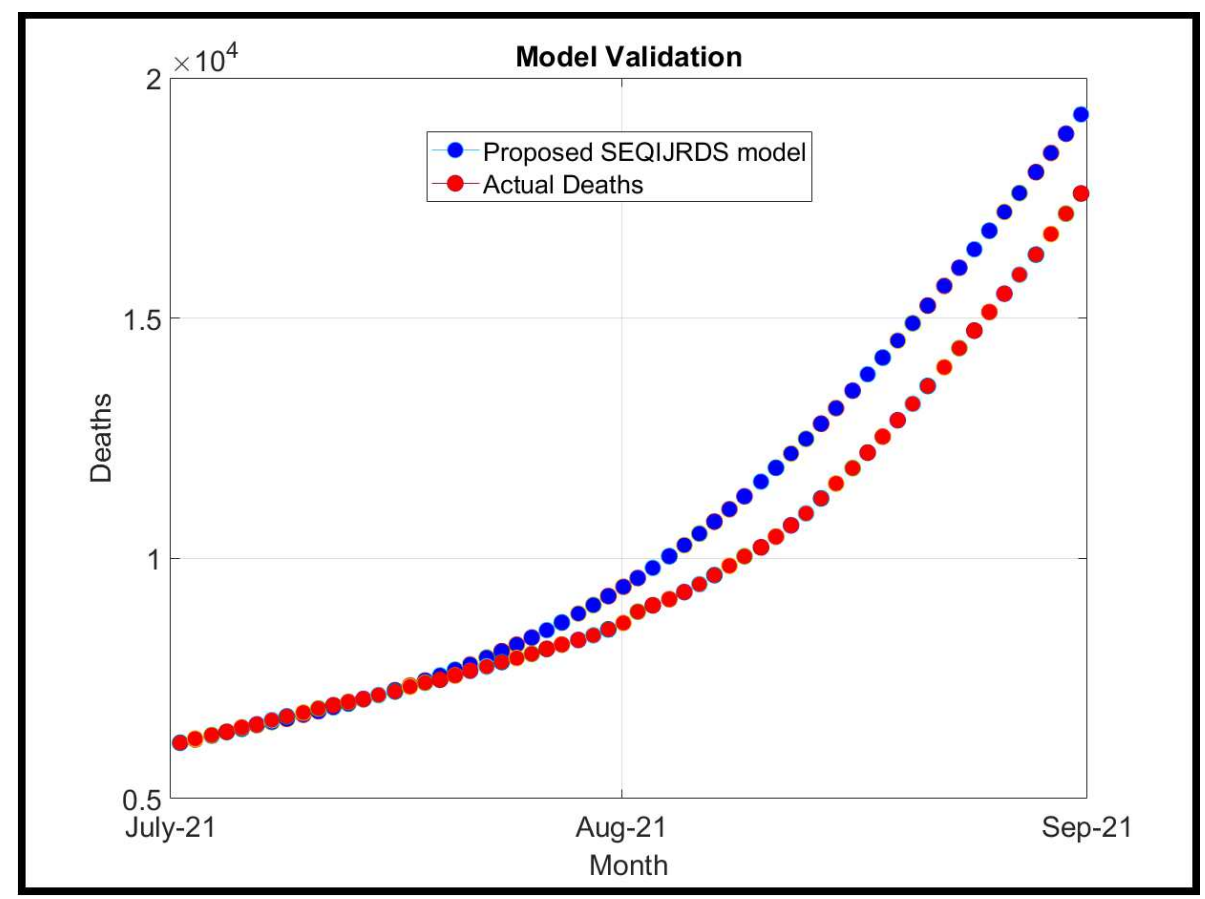

Figure 13. Graph showing comparison of actual deaths with the deaths predicted by proposed SEQIJRDS mode

As proved graphically in Figure 13; MAPE is low for the first 4 weeks and gradually increases there onwards which agrees with the typical behavior of forecasting models. Table 3 shows the summary of results for this metric and a comparison with state of the art prediction model's MAPE for South East, East Asia and Oceania region which is the closest region to Sri Lanka in the study done in [53].

From the result in Table 3; it is clear that the proposed model has a prediction performance inferior to the SIKJalpha model and outperform the Imperial model and IHME models. It can be observed that the MAPE is less than 1 within the first 2 weeks and less than 2 within the first month suggesting that the accuracy of the predictions is high within the first 4 weeks of prediction. The accuracy of the proposed model is sufficient enough to decide the public health interventions in Sri Lanka. 
We further predict for 2 months ahead from $31^{\text {st }}$ August 2021 and compare the daily death rate predictions with those predicted by Institute for Health Metrics and Evaluation (IHME) for worst case scenarios. That is vaccination is stopped, no lockdowns for the next two months, no enhancement of quarantine measures. We first collected the IHME predictions from the source [54]. We then plot and compare the proposed model's performance Vs. IHME for future predictions as shown in the Figure 14.

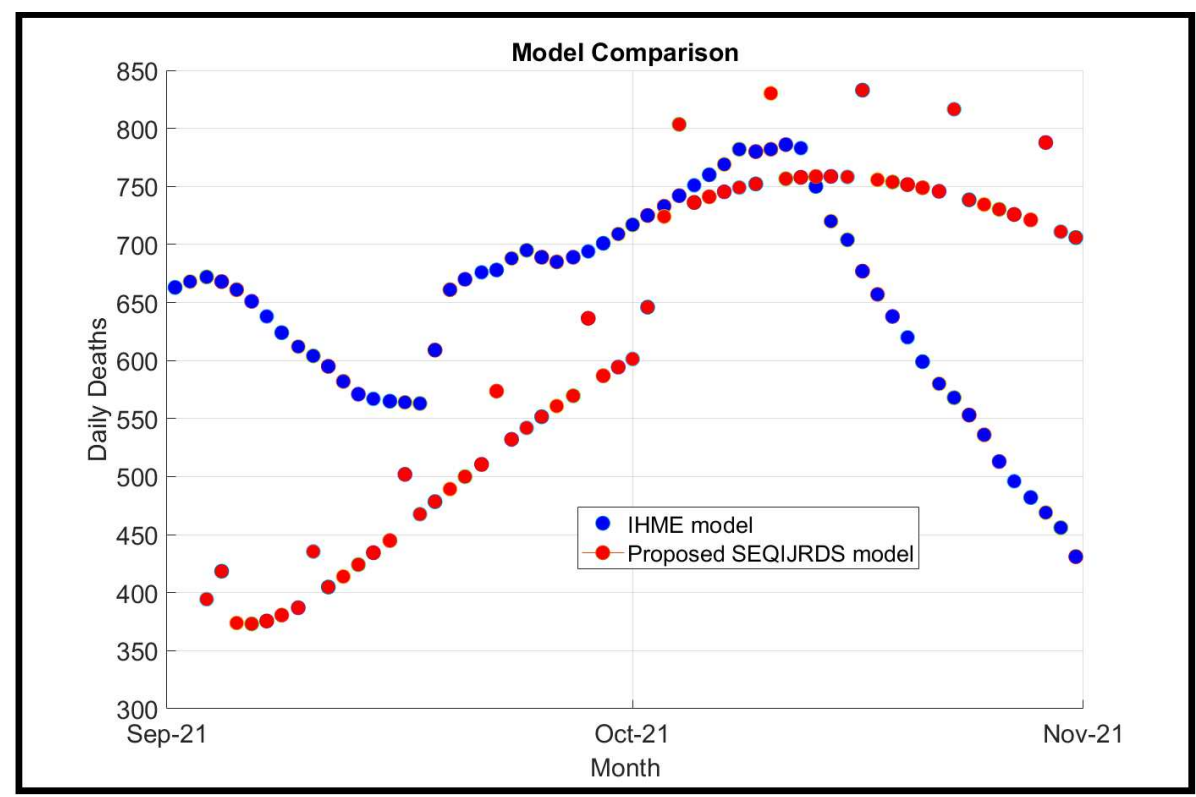

Figure 14. Comparison of daily death prediction of the proposed model and IHME model

As an effect measure; we compute the standardized mean difference between predictions of the two models. We use the Equation 12 to compute the mean difference.

$$
\text { Standardized Mean Difference }=\frac{M_{1}-M_{2}}{S D_{\text {pooled }}}
$$

The SMD between the two predictions is 0.25 indicating there is only a small difference between the prediction values of the two models.

\subsection{Mortality rate Predictions}

\subsubsection{Using Lockdowns}

At the time of writing (on August 29 2021); We predict the number of deaths using the epidemiology model proposed in the methodology under 9 scenarios. Those are not locking down and locking down for $x$ weeks starting from first week of September 2021. Considering weekly lock downs is very appropriate as lockdown decisions by the government of Sri Lanka is taken in week basis. The obtained results for death predictions are as given in Figure 15. In order to study the effect of mobility only; we assume that no vaccination is continued during September and October. For no-lockdown case; we set the mobility as average mobility under no-lockdown scenario $(\mu=0.67)$ and for a lockdown week we set the $(\mu=0.34)$ as explained in the methodology section. The results are as seen in Figure 15. These are generated for the universal mask use case $(M=0.05)$.

We will compare the deaths at the end of November in this analysis. It should be noted that these deaths are the real deaths with adjustment for under-reporting. So, as evident from Figure 15; 7982 deaths can be avoided by the end of November just by locking down the first week of September. The difference in death reduction for each week of lock-down increases for the first 3 weeks, insignificant 


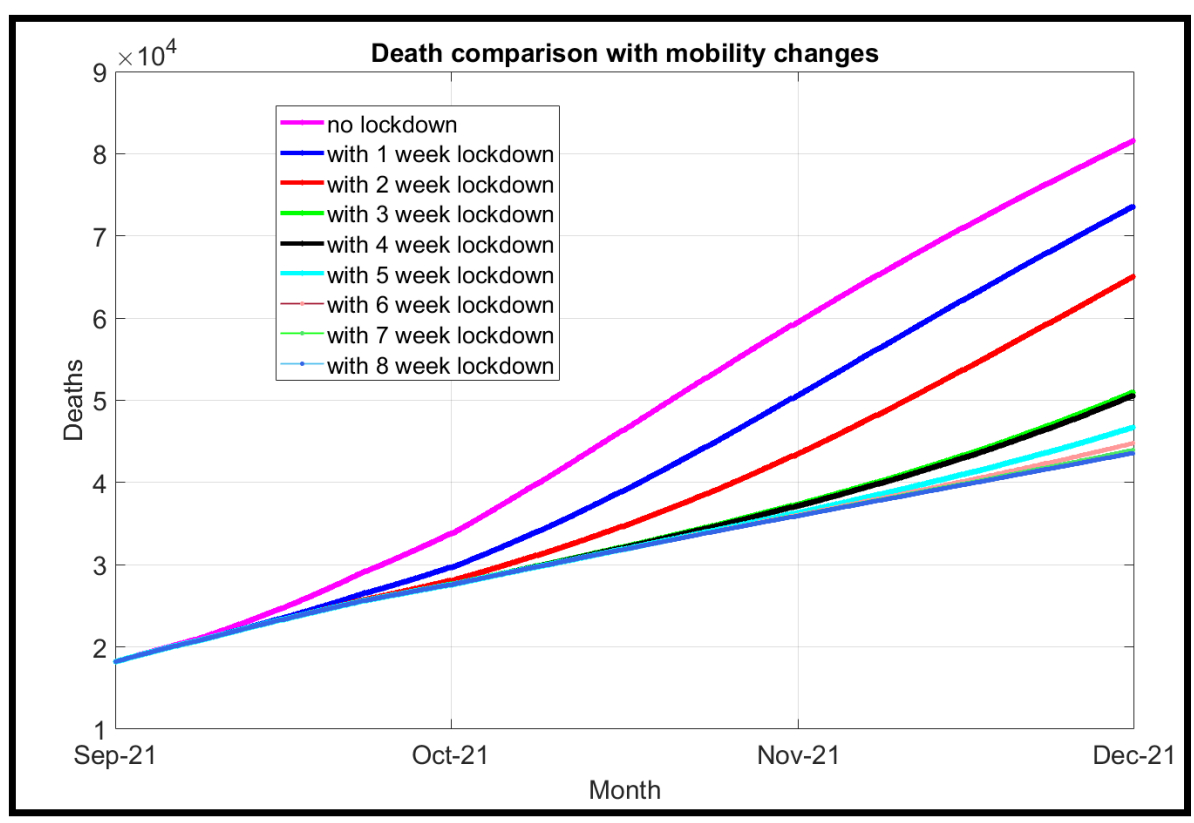

Figure 15. Comparing mortality under different mobility related health interventions

for the 4th week and the gap becomes lesser afterwards. This indicates the very high requirement for implementing the entire country lock down during the first 3 weeks. Total deaths which can be averted by locking down 3 weeks is 30,560. So, this period of 3 weeks can be set as the minimum lock-down period since it can avoid a massacre of human lives. However even though the death reduction in 4 th week is insignificant if the lock down can be continued until the sixth week continuously; additional 6200 people's lives can be saved at the end of November which is a significant number of human lives. Therefore, the recommended period of lockdown can be inferred as 6 weeks. It is very clear that continuing locking down for the 7th and 8 weeks only saves 1220 human lives. Even though this number of human lives matter; considering the negative impact on Economy, education, mental health etc. the government may not implement lockdown in last 2 weeks of October.

\subsubsection{Effect of Vaccination}

At the time of writing (on August $29^{\text {th }}$ 2021); We predict the number of deaths using the epidemiology model proposed in the methodology under 2 scenarios. One of them is continuing vaccination for the next 2 months only. Here we consider that vaccination rate will be at average case $(\eta=0.0083)$. The other is vaccination is stopped for the next 2 months. In order to study the effect of vaccination only; we assume that no lockdown is implemented during September and October. The results are as seen in Figure 16. These are generated for the universal mask use case $(\mathrm{M}=0.05)$. We have assumed a vaccination efficacy of 0.5 as it was said in the methodology section. 


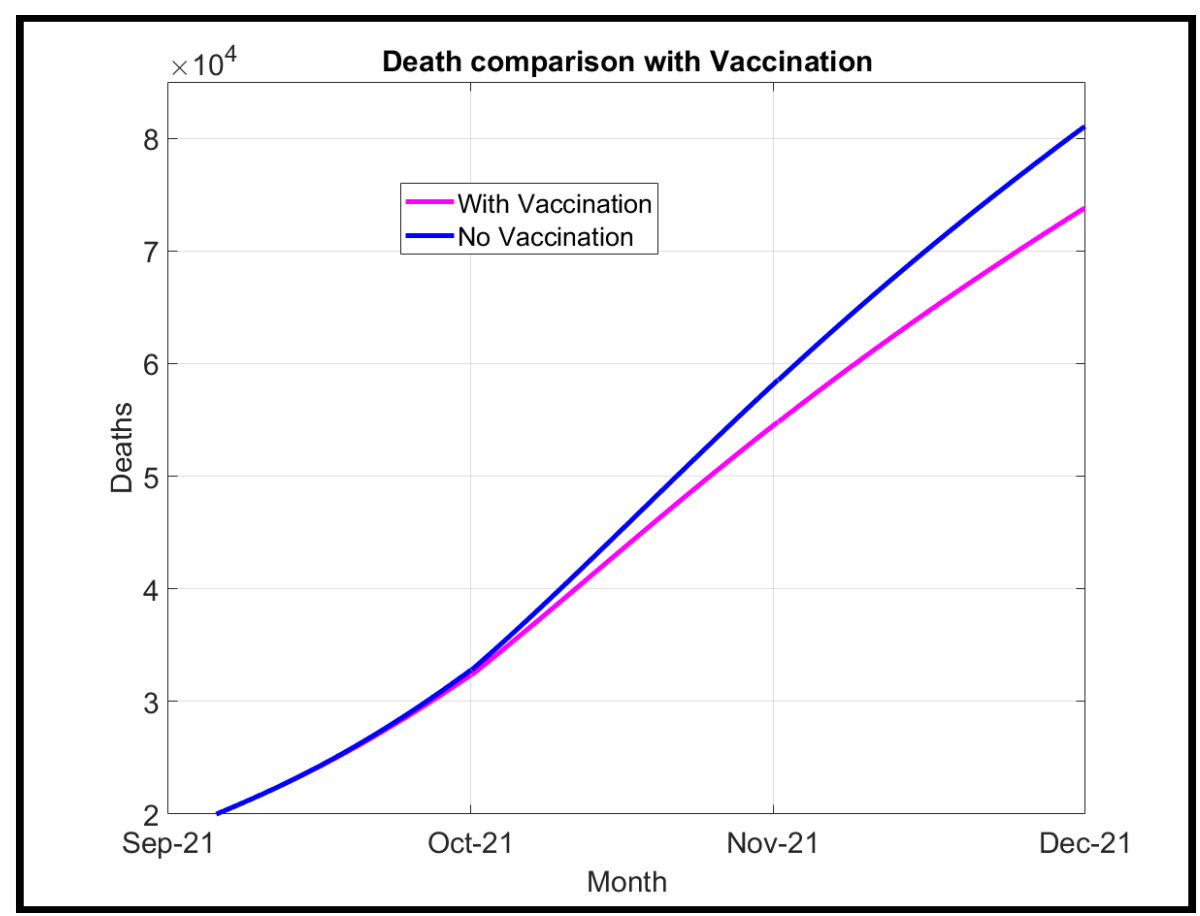

Figure 16. Graph showing the effect of vaccination on future mortality

So, as evident from Figure 16; 7230 people's lives can be saved if Sri Lanka continues the current process of vaccination without implementing any lock down for the next two months and do not change the existing quarantine and contact tracing rate. Hence, locking down the country alone for 3 weeks saves 23330 more lives than entire 2 months of vaccination by the end of November.

\subsubsection{Effect of Contact tracing and quarantine}

At the time of writing (on August 29 2021); We predict the number of deaths using the epidemiology model proposed in the methodology under 3 scenarios. One of them is $50 \%$ enhancement of the existing contact tracing process for the next 2 months ( $\mathrm{gamma}_{0}=0.333$ ). The second one is $100 \%$ enhancement (doubling) of contact tracing and quarantining $\left(g a m m a_{0}=0.44\right)$ for next two months. In order to study the effect of contact tracing only; we assume that no lockdown is implemented and vaccination is stopped during September and October. The results are as seen in Figure 17. These are generated for the universal mask use case $(M=0.05)$. 


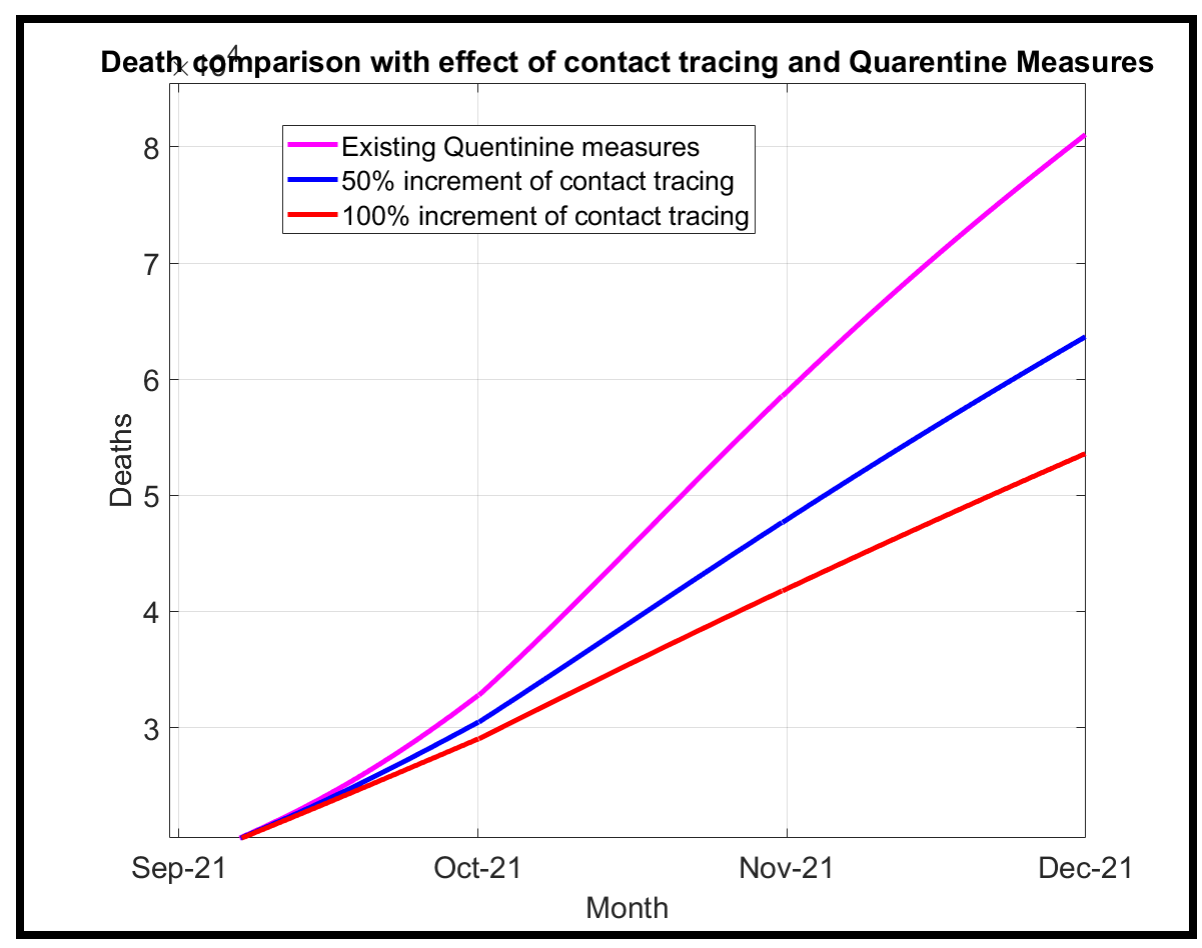

Figure 17. Comparing different levels of quaratine and contact tracing's effect on mortality

So, as evident from Figure 17; nearly 17503 people's lives can be saved by the end of November if Sri Lanka enhances the current process of quarantine and contact tracing by $50 \%$ for next two months. On the other hand; 9914 more additional lives can be saved by doubling existing quarantine measures for two months resulting a total of 27417 lifesaving. But still the lifesaving is less than 3 week entire country lockdown only.

\subsection{Hospital Resource usage predictions}

Another important parameter when taking decisions is the hospital resource demand which can be measured by inward patients for COVID-19. We predict the admitted patients under different public health intervention scenarios as shown in Figure 18.

- scenario 1 - With no lockdown, existing contact tracing, stop vaccination

- scenario 2 - one month lockdown, double existing contact tracing for two months, continue vaccination

- scenario 3 - two month lockdown, 50\% enhancement of existing contact tracing, continue vaccination 


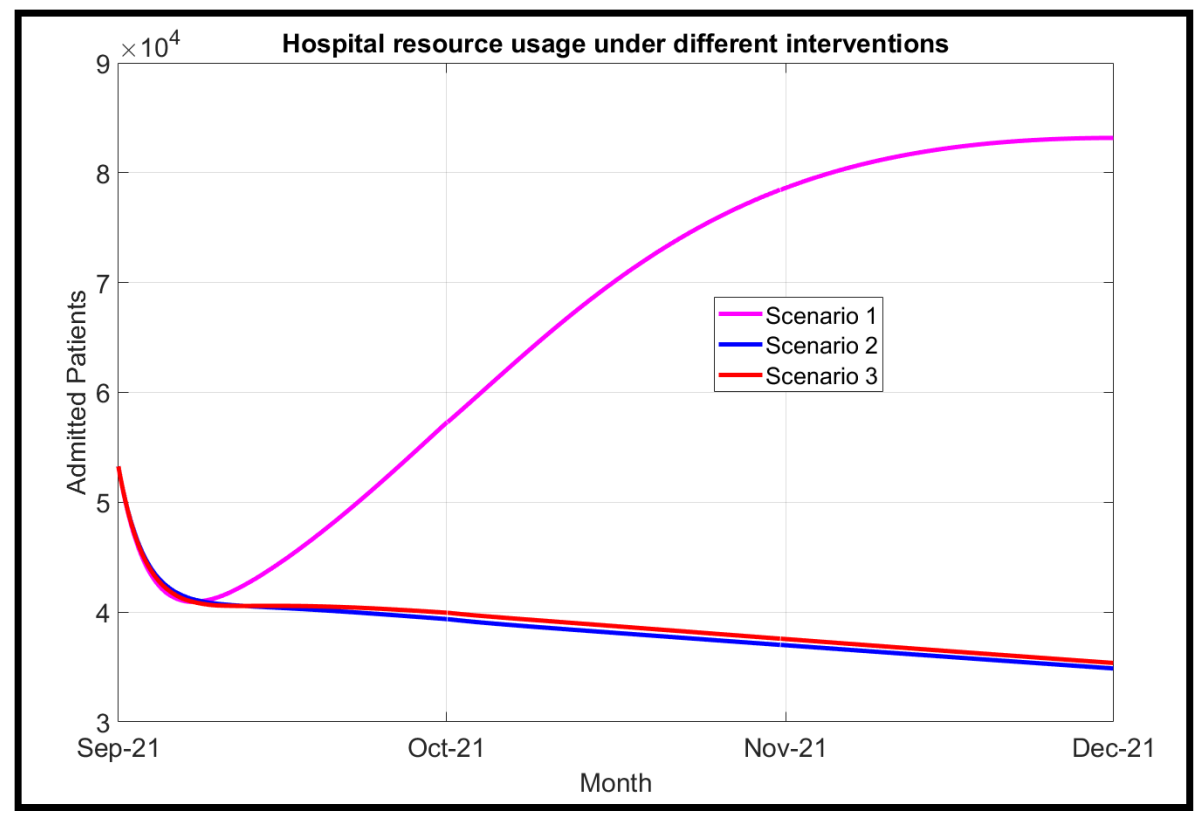

Figure 18. Comparison of Hospital resource usage under different scenarios

It can be observed that there will be $83168,34874,35393$ people residing in hospitals at the end of November under scenario1, scenario 2 and scenario 3 respectively. Hence, the scenario 2 can be observed as the best option since it gives the minimum admitted patients. However, due to the practical difficulties which may arise when doubling quarantine measures; scenario 3 may be considered as a sub-optimal solution since the death difference between scenario 2 and scenario 3 are not much different.

\section{Discussion}

\subsection{General interpretation of the results in the context of other evidence.}

In result section we have noticed how each lockdown, vaccination, quarantine measures individually affect the future mortality. Now, let us derive the recommendations based on those results. Since we derived minimum lockdown requirement of 3 weeks and optimum lockdown period of 6 weeks; here we will combine other interventions with previously said 2 interventions. We will form 3 recommendations as follows.

- Minimum Recommendation- 3 Week lockdown, stop vaccination, continue existing quarantine and contact tracing

- Sub-optimum Recommendation - 6 Week lockdown, continue vaccination,50\% enhancement of quarantine measures

- Optimum Recommendation - Entire 2 month lockdown, continue vaccination, 100\% increment of quarentine measures

We will now compare the parameter daily deaths for above 3 recommendations against the worst case of continuing existing quarantine only to obtain the following result shown in Figure 19

It is evident from Figure 19 that the daily deaths for the months of September, October are comparatively low for all the recommendations. However, for the minimum recommendation; daily deaths gradually increase to the level of worse case by the end of November. Therefore, if minimum recommendation is implemented there will be an additional requirement to impose another lock-down before December to prevent rising of daily deaths and death count. On the other hand, both sub-optimal and optimal solution not only will be able to reduce number of deaths; but also, they have successfully prevented further spreading of the disease by the beginning of December. As seen from the results 


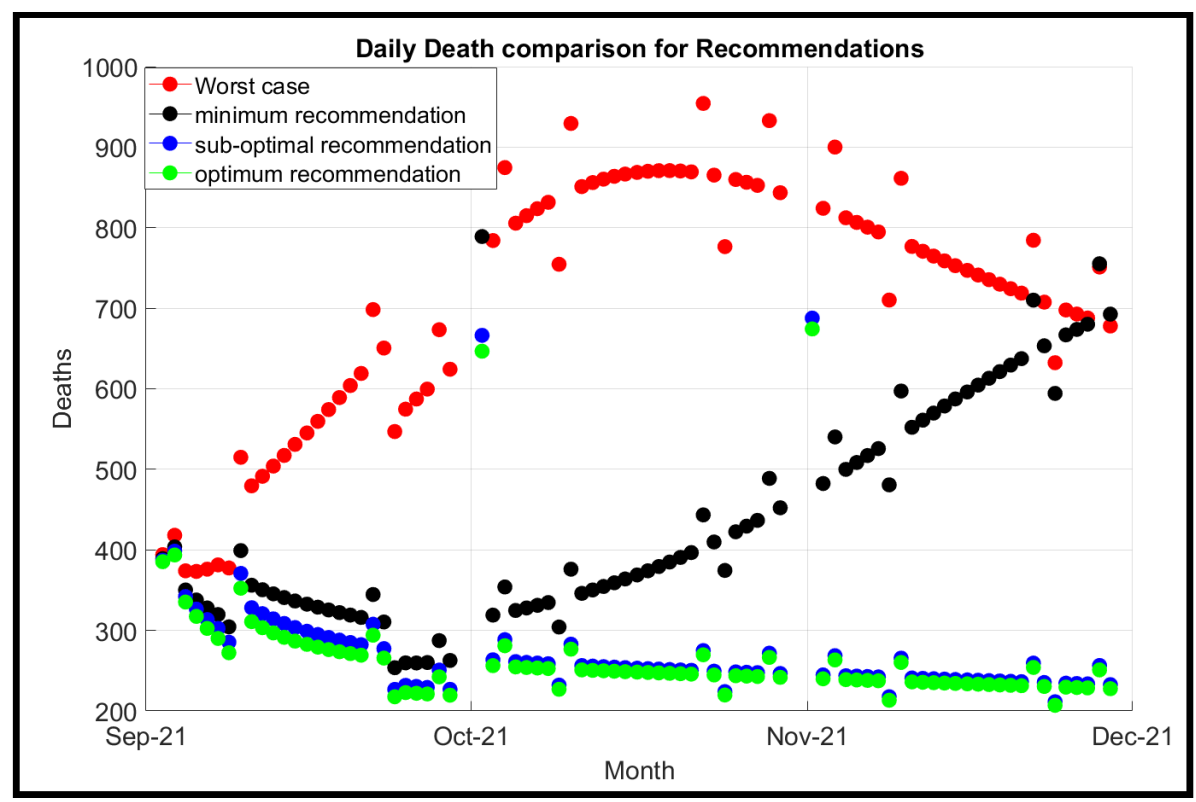

Figure 19. Comparison of Hospital resource usage under different scenarios

All other parameters which are not specified in Table 4 are derived using the data after a statistical analysis or directly from the data.

in Figure 19; for both solutions it can be observed decreasing daily deaths by the end of November indicating that spreading of the disease has been properly controlled by both sub optimal and optimum solutions. Further, it can be observed a little difference in optimum and sub-optimum solution. Therefore, considering negative impacts that are caused due to intervention on numerous sectors such as economy, education, mental health etc.; government may consider implementing sub-optimal solution instead of optimal solution. We categorize it as optimum solution only considering the number of deaths and death rate as mentioned here. However, as mentioned sub-optimal recommendation may be more appropriate when considering other negative impacts from COVID19.

\subsection{Limitations of the evidence}

As it was mentioned separately in detail in the methodology section, we summarize the assumed or derived/learned parameters for the model due to lack of data as shown in Table 4.

Table 4. Table of Estimated and Learned Parameters

\begin{tabular}{|c|c|c|}
\hline Parameter & Learned & Assumed \\
\hline$\beta_{0}=0.000006415$ & yes & no \\
\hline$\gamma_{0}=0.22$ & yes & no \\
\hline$\alpha_{1}=0.3$ & yes & no \\
\hline$P_{S}=0.5$ & no & yes \\
\hline$P_{I}=0.3$ & no & yes \\
\hline$P_{J}=0.3$ & no & yes \\
\hline$\epsilon_{E}=1.0 e(-7)$ & no & yes \\
\hline$\epsilon_{Q}=1.0 e(-7)$ & no & yes \\
\hline$\epsilon_{J}=1.0 e(-7)$ & no & yes \\
\hline$k_{1}=0.01$ & yes & no \\
\hline$\gamma_{2}=0.05$ & yes & no \\
\hline$\alpha_{3}$ & no & yes \\
\hline
\end{tabular}




\subsection{Limitations of the model and future work}

The model does not take the following factors into consideration. They are remaining to be addressed as a future work.

\section{Dependence of Death fraction}

The proposed model assumes a mean death fraction without considering the variation by gender and age.

\section{Population Density as a contributor for $\beta$}

The model could represent a node in a graph of nodes which could be summed to get the final output for a local region. For instance, for Sri Lanka, a graph of nodes representing districts with different population densities could be simulated and summed to get the final output at the end. In such a scenario, inter-node travel should also be considered and model can get complex and erroneous. Based on non-availability of exact population in districts and non-availability of COVID19 data and mobility data divided across districts; we refrain from modeling in this procedure.

\section{Conclusion}

This paper presented a mathematical epidemiological model called SEQIJRDS. Once the hyper parameters are learned and tuned, the model can predict mortality rates with a 4-week MAPE less than $2 \%$ resulting a performance better than other SEIR models. When considering the current situation of Sri Lanka; according to the predictions of the model and comparing other impacts to the country, I suggest that the best intervention is to lock down the country for entire October and 2 more weeks in September 2021 with continuing the vaccination process and tightening the existing quarantine measures resulting drastic reduction in both cumulative deaths of valuable human lives and death rate.

\section{Other information}

\subsection{Support}

This research did not receive any financial support. This was conducted with the expenses of the sole author.

\section{2. author contributions}

conceptualization - P.A.D.S.N. Wijesekara; methodology - P.A.D.S.N.W.; software, P.A.D.S.N.W.; validation - P.A.D.S.N.W. - formal analysis - P.A.D.S.N.W.; investigation - P.A.D.S.N.W.; resources - P.A.D.S.N.W.; data curation - P.A.D.S.N.W.; writing-original draft preparation - P.A.D.S.N.W. ; writing-review and editing - P.A.D.S.N. Wijesekara; visualization - P.A.D.S.N.W.; supervision - None

\subsection{Competing interests}

No conflict of interest.

\subsection{Availability of data, code, and other materials}

Data, code will be available after publication from the author.

\section{References}

1. Ranasinghe R. Post-covid19 (novel corona) economic recovery: Critical review on economic immunity of Sri Lanka. Available at SSRN 3587179. 2020 Apr 28. 
2. Rahimi, R., Dolatabadi, Z., Moeindarbary, S., Behzadfar, S., Fakhr Ghasemi, N., Tafrishi, R. and Kamali, M., 2020. A systematic review of the prevalence of mental health disorders in pregnant women during the COVID-19 pandemic. International Journal of Pediatrics, 8(11), pp.12397-12407.

3. Kumar, D., Malviya, R. and Sharma, P.K., 2020. Corona virus: a review of COVID-19. EJMO, 4(1), pp.8-25.

4. Yuki, K., Fujiogi, M. and Koutsogiannaki, S., 2020. COVID-19 pathophysiology: A review. Clinical immunology, 215, p.108427.

5. Kumar, A., Gupta, P.K. and Srivastava, A., 2020. A review of modern technologies for tackling COVID-19 pandemic. Diabetes \& Metabolic Syndrome: Clinical Research \& Reviews, 14(4), pp.569-573.

6. Brodeur, A., Gray, D., Islam, A. and Bhuiyan, S., 2020. A literature review of the economics of COVID-19. Journal of Economic Surveys.

7. Hafeez, A., Ahmad, S., Siddqui, S.A., Ahmad, M. and Mishra, S., 2020. A review of COVID-19 (Coronavirus Disease-2019) diagnosis, treatments and prevention. EJMO, 4(2), pp.116-125.

8. Gallo Marin, B., Aghagoli, G., Lavine, K., Yang, L., Siff, E.J., Chiang, S.S., Salazar-Mather, T.P., Dumenco, L., Savaria, M.C., Aung, S.N. and Flanigan, T., 2021. Predictors of COVID-19 severity: A literature review. Reviews in medical virology, 31(1), pp.1-10.

9. Rod, J.E., Oviedo-Trespalacios, O. and Cortes-Ramirez, J., 2020. A brief-review of the risk factors for covid-19 severity. Revista de saude publica, 54 .

10. Pradhan, D., Biswasroy, P., Naik, P.K., Ghosh, G. and Rath, G., 2020. A review of current interventions for COVID-19 prevention. Archives of medical research, 51(5), pp.363-374.

11. Chakraborty, R. and Parvez, S., 2020. COVID-19: An overview of the current pharmacological interventions, vaccines, and clinical trials. Biochemical pharmacology, p.114184.

12. Xiang, Y., Jia, Y., Chen, L., Guo, L., Shu, B. and Long, E., 2021. COVID-19 epidemic prediction and the impact of public health interventions: A review of COVID-19 epidemic models. Infectious Disease Modelling.

13. Bo, Y., Guo, C., Lin, C., Zeng, Y., Li, H.B., Zhang, Y., Hossain, M.S., Chan, J.W., Yeung, D.W., Kwok, K.O. and Wong, S.Y., 2021. Effectiveness of non-pharmaceutical interventions on COVID-19 transmission in 190 countries from 23 January to 13 April 2020. International Journal of Infectious Diseases, 102, pp.247-253.

14. Duhon, J., Bragazzi, N. and Kong, J.D., 2021. The impact of non-pharmaceutical interventions, demographic, social, and climatic factors on the initial growth rate of COVID-19: A cross-country study. Science of The Total Environment, 760, p.144325.

15. Askitas, N., Tatsiramos, K. and Verheyden, B., 2021. Estimating worldwide effects of non-pharmaceutical interventions on COVID-19 incidence and population mobility patterns using a multiple-event study. Scientific reports, 11(1), pp.1-13.

16. Lopez-Leon, S., Wegman-Ostrosky, T., Perelman, C., Sepulveda, R., Rebolledo, P.A., Cuapio, A. and Villapol, S., 2021. More than 50 Long-term effects of COVID-19: a systematic review and meta-analysis. Available at SSRN 3769978.

17. Sooriyaarachchi, P., Francis, T.V., King, N. and Jayawardena, R., 2021. Increased physical inactivity and weight gain during the COVID-19 pandemic in Sri Lanka: An online cross-sectional survey. Diabetes \& Metabolic Syndrome: Clinical Research \& Reviews, 15(4), p.102185.

18. Jayaweera, M., Dannangoda, C., Dilshan, D., Dissanayake, J., Perera, H., Manatunge, J. and Gunawardana, B., 2021. Grappling with COVID-19 by imposing and lifting non-pharmaceutical interventions in Sri Lanka: A modeling perspective. Infectious Disease Modelling.

19. Wijesekara, N.W.A.N.Y., Herath, N., Kodithuwakku, P.D., Herath, H.D.B., Ginige, S., Ruwanpathirana, T., Kariyawasam, M., Samaraweera, S., Herath, A., Jayawardena, S. and Gamge, D., 2020. COVID-19 Case Prediction and Outbreak Control of Navy Cluster in Sri Lanka: Effectiveness of SIR Model.

20. Jayatissa, R., Herath, H.P., Perera, A.G., Dayaratne, T.T., De Alwis, N.D. and Nanayakkara, H.P.L.K., 2021. Impact of COVID-19 on child malnutrition, obesity in women and household food insecurity in underserved urban settlements in Sri Lanka: a prospective follow-up study. Public Health Nutrition, pp.1-9.

21. Saeed, R., Amin, F., Talha, M., Randenikumara, S., Shariff, I., Durrani, N. and Salman, S., 2021. Covid-19 pandemic prevalence and risk factors for depression among health care workers in South Asia. Asia Pacific Journal of Public Health, p.10105395211002324.

22. MR, T.S., Ahammed, T., Anjum, A., Chowdhury, A.A. and Suchana, A.J., 2020. Finding the real COVID-19 case-fatality rates for SAARC countries. 
23. Marzo, R.R., Ismail, Z., Htay, M.N.N., Bahari, R., Ismail, R., Villanueva III, E.Q., Singh, A., Lotfizadeh, M., Respati, T., Irasanti, S.N. and Sartika, D., 2021. Psychological distress during pandemic Covid-19 among adult general population: Result across 13 countries. Clinical Epidemiology and Global Health, 10, p.100708.

24. Sarkar, A., Liu, G., Jin, Y., Xie, Z. and Zheng, Z.J., 2020. Public health preparedness and responses to the coronavirus disease 2019 (COVID-19) pandemic in South Asia: a situation and policy analysis. Global Health Journal, 4(4), pp.121-132.

25. Ministry of Health Sri Lanka. Provisional Clinical Practice Guidelines on COVID-19 suspected and confirmed patients [Internet], 2020.,Available at: https: / / www.epid.gov.lk/web/images/pdf/Circulars/Corona_virus / covid-19_cpg_version_5.pdf, Accessed on 14.08.2021

26. Erandi, K.K.W.H., Mahasinghe, A.C., Perera, S.S.N. and Jayasinghe, S., 2020. Effectiveness of the strategies implemented in Sri Lanka for controlling the COVID-19 outbreak. Journal of Applied Mathematics, 2020.

27. Tyrrell, C.S., Mytton, O.T., Gentry, S.V., Thomas-Meyer, M., Allen, J.L.Y., Narula, A.A., McGrath, B., Lupton, M., Broadbent, J., Ahmed, A. and Mavrodaris, A., 2021. Managing intensive care admissions when there are not enough beds during the COVID-19 pandemic: a systematic review. Thorax, 76(3), pp.302-312.

28. Sheain Fernandopulle, Six COVID-19 variants so far identified in Sri Lanka, Available at: https://www. dailymirror.1k/top_story/Six-COVID-19-variants-so-far-identified-in-Sri-Lanka/155-211603, Accessed on 14.08.2021.

29. Lineage List,Available at: https:/ / cov-lineages.org/lineage_list.html, Accessed on 14.08.2021

30. B.1.617.2 2021-05-19,Available at: https://cov-lineages.org/global_report_B.1.617.2.html, Accessed on 14.08 .2021

31. B.1.525 2021-07-30,Available at: https://cov-lineages.org/global_report_B.1.525.html, Accessed on 14.08.2021

32. Chanka Jayasinghe,"UK, Danish, South African COVID-19 strains found in 12 samples in Sri Lanka",Available at: https: / / economynext.com/uk-danish-south-african-covid-19-strains-found-in-12-samples-in-sri-lanka$80645 /$, Accessed on 14.08.2021

33. B.1.1.7 2021-07-30,Available at: https://cov-lineages.org/global_report_B.1.1.7.html, Accessed on 14.08.2021

34. B.1.351 2021-07-30,Available at: https://cov-lineages.org/global_report_B.1.351.html, Accessed on 14.08.2021

35. Department of Census and Statistics, Sri Lanka, "Population,Available at: "http://www.statistics.gov. lk/GenderStatistics/StaticalInformation/Population/PopulationbyAgeGroupsandSex2012, Accessed on 14.08.2021.

36. "Sri Lanka Population,Available at: "https://www.worldometers.info/world-population/sri-lankapopulation/", Accessed on 14.08.2021.

37. Yang, L., Dai, J., Zhao, J., Wang, Y., Deng, P. and Wang, J., 2020. Estimation of incubation period and serial interval of COVID-19: analysis of 178 cases and 131 transmission chains in Hubei province, China. Epidemiology \& Infection, 148.

38. Ministry of Health - Sri Lanka, Corona Virus 2020 / 2021, Available at: https://www.epid.gov.lk/web/ index.php?option=com_content\&view=article\&id=225\&lang=en, Accessed on 01.07.2021 - 31.08.2021

39. Google LLC "Google COVID-19 Community Mobility Reports"., Available at: https:/ /www.google.com/ covid19/mobility/ Accessed on 21/08/2021.

40. Zulfick Farzan, Sri Lanka identifies 03 new mutations of Delta COVID variant, Available at: https:// www.newsfirst.lk/2021/08/17/sri-lanka-identifies-03-new-mutations-of-delta-covid-variant/, Accessed on $21 / 08 / 2021$

41. COVID-19 pandemic - Sri Lanka, Available at: https://global-monitoring.com/gm/page/events/epidemic0002015.fTDtGCxti2qN.html?lang=en, Accessed on 21/08/2021

42. GARDAWORLD, Sri Lanka: First locally transmitted COVID-19 case March 11 / update 3, Available at: https:/ / www.garda.com/crisis24/news-alerts/321466/sri-lanka-first-locally-transmitted-covid-19-casemarch-11-update-3, Accessed on 21.08.2021

43. GARDAWORLD, Sri Lanka: Nationwide curfew implemented March 20-23 / update 5,Available at: https://www.garda.com/crisis24/news-alerts/324931/sri-lanka-nationwide-curfew-implementedmarch-20-23-update-5, Accessed on 21.08.2021 
44. GARDAWORLD,Sri Lanka: Authorities to ease COVID-19 restrictions April 20, 22 /update 11, Available at: https: / /www.garda.com/crisis24/news-alerts/334206/sri-lanka-authorities-to-ease-covid19-restrictions-april-20-22-update-11, Accessed on 21.08.2021

45. GARDAWORLD,Sri Lanka: Lockdown restrictions to be eased May 11 /update 15,Available at: https:/ / www.garda.com/crisis24/news-alerts/340666/sri-lanka-lockdown-restrictions-to-be-easedmay-11-update-15, Accessed on 21.08.2021

46. GARDAWORLD,Sri Lanka: Authorities to implement nationwide lockdown May 24-May 26 / update 16, Available at: https:/ / www.garda.com/crisis24/news-alerts/344756/sri-lanka-authorities-to-implementnationwide-lockdown-may-24-may-26-update-16, Accessed on 21.08.2021

47. GARDAWORLD,Sri Lanka: Authorities tighten travel restrictions October 18 / update 23,Available at: https:/ / www.garda.com/crisis24/news-alerts/390666/sri-lanka-authorities-tighten-travel-restrictionsoctober-18-update-23, Accessed on 21.08.2021

48. GARDAWORLD, Sri Lanka: Authorities impose indefinite curfew in Gampaha district towns on October 4 /update 19, Available at: https:/ / www.garda.com/crisis24/news-alerts/386006/sri-lanka-authoritiesimpose-indefinite-curfew-in-gampaha-district-towns-on-october-4-update-19, Accessed on 21.08.2021

49. Allen, L.J., Brauer, F., Van den Driessche, P. and Wu, J., 2008. Mathematical epidemiology (Vol. 1945). Berlin: Springer.

50. World Health Organization, Vaccine efficacy, effectiveness and protection, Available at: https://www. who.int/news-room/feature-stories/detail/vaccine-efficacy-effectiveness-and-protection, Accessed on 24.08.2021

51. Campbell, F., Archer, B., Laurenson-Schafer, H., Jinnai, Y., Konings, F., Batra, N., Pavlin, B., Vandemaele, K., Van Kerkhove, M.D., Jombart, T. and Morgan, O., 2021. Increased transmissibility and global spread of SARS-CoV-2 variants of concern as at June 2021. Eurosurveillance, 26(24), p.2100509.

52. Dharmaratne, S., Sudaraka, S., Abeyagunawardena, I., Manchanayake, K., Kothalawala, M. and Gunathunga, W., 2020. Estimation of the basic reproduction number (R0) for the novel coronavirus disease in Sri Lanka. Virology Journal, 17(1), pp.1-7.

53. Friedman, J., Liu, P., Troeger, C.E., Carter, A., Reiner, R.C., Barber, R.M., Collins, J., Lim, S.S., Pigott, D.M., Vos, T. and Hay, S.I., 2021. Predictive performance of international COVID-19 mortality forecasting models. Nature communications, 12(1), pp.1-13.

54. Excess daily deaths, Available at: https:/ / covid19.healthdata.org/sri-lanka?view=daily-deaths\&tab=trend, Accessed on 29.08.2021

55. Ediriweera, D.S., De Silva, N.R., Malavige, G.N. and De Silva, H.J., 2020. An epidemiological model to aid decision-making for COVID-19 control in Sri Lanka. PLoS One, 15(8), p.e0238340

56. World Health Organization, The true death toll of COVID-19,Available at: https://www.who.int/data/ stories/the-true-death-toll-of-covid-19-estimating-global-excess-mortality, Accessed on 28.03.2021

57. Srivastava, A., Xu, T. and Prasanna, V.K., 2020. Fast and Accurate Forecasting of COVID-19 Deaths Using the SIkJ $\alpha$ Model. arXiv preprint arXiv:2007.05180.

58. COVID, I. and Murray, C.J., 2020. Forecasting COVID-19 impact on hospital bed-days, ICU-days, ventilator-days and deaths by US state in the next 4 months. MedRxiv.

59. Watson, O.J., Winskill, P., Brazeau, N., Fitzjohn, R., Walker, P.G.T. and Hereñú, D., mrc-ide/squire: v0. 4.34.

60. bettercare.co.za. (n.d.)., COVID-19. [online] Available at: Available at: https://bettercare.co.za/learn/ infection-prevention-and-control/text/10.html, Accessed 6 Jul. 2021.

61. Wickramaarachchi, W.P.T.M., Perera, S.S.N. and Jayasinghe, S., 2020. COVID-19 epidemic in Sri Lanka: A mathematical and computational modelling approach to control. Computational and Mathematical Methods in Medicine, 2020.

62. Alene, M., Yismaw, L., Assemie, M.A., Ketema, D.B., Mengist, B., Kassie, B. and Birhan, T.Y., 2021. Magnitude of asymptomatic COVID-19 cases throughout the course of infection: A systematic review and meta-analysis. PloS one, 16(3), p.e0249090.

63. Shihar Aneez, Garment workers on front line of Sri Lanka coronavirus outbreak, Available at: https://www. reuters.com/article/us-health-coronavirus-sri-lanka-workers-idUSKBN27K08Z, Accessed on 08.07.2021

64. 5921 Positive Cases Still in Hospitals - NOCPCO, Available at: https:/ / covid19.gov.lk/news/health/5921positive-cases-still-in-hospitals-nocpco.html, Accessed on 08.07.2021 
65. Fernando, J.L.I.N., Wickramaratne, C.P., Dissanayake, R.S.B., Kolambage, S.H., Aminda, M.A.U., Cooray, N.H., Hamzahamed, K., Haridas, P.M., Jayasinghe, J.M.L., Mowjood, M.S. and Muthukudaarachchi, A.D., 2012. Studying current status of intensive care services in Sri Lanka. International journal of critical illness and injury science, 2(1), p.11.

66. Wimalaweera, A., 2020. Covid 19 \& Beyond-The impact on the Labour Market of Sri Lanka. Sri Lanka: Department Of Labour, Sri Lanka.

67. Roshana, M., Kaldeen, M. and Banu, A.R., 2020. Impact of COVID-19 outbreak on Sri Lankan Economy. Journal of Critical Reviews, 7(14), pp.2124-2133.

68. KPMG. (2020). Impact on Covid 19 on the Sri Lankan Economy - KPMG Sri Lanka. [online] Available at: https://home.kpmg/lk/en/home/insights/2020/04/impact-on-covid-19-on-the-sri-lankan-economy. html., accessed on 20.07.2021

69. Rameez, A., Fowsar, M.A.M. and Lumna, N., 2020. Impact of Covid-19 on Higher Education Sectors in Sri Lanka: A Study based on South Eastern University of Sri Lanka.

70. Chandasiri, O., 2020. The COVID-19: impact on education. Journal of Asian and African Social Science and Humanities, 6(2), pp.38-42.

71. Sri Lanka tourism earnings fall in February due to COVID-19, http:/ / www.xinhuanet.com/english/202005/18/c_139067173.htm, accessed on 15.07.2021

72. Sri Lanka Tourist Arrivals, https://tradingeconomics.com/sri-lanka/tourist-arrivals, accessed on 17.07.2021

73. Mombauer, D. (2020) 'Aided by weather, Sri Lanka's lockdown leads to decline in air, sea pollution'. Available at: https:/ /news.mongabay.com/2020/05/aided-by-weather-sri-lankas-lockdown-leads-to-decline-in-airsea-pollution/, accessed on 19.07.2021

(C) 2021 by the authors. Submitted to Nature Human Behaviour for possible open access publication under the terms and conditions of the Creative Commons Attribution (CC BY) license (http://creativecommons.org/licenses/by/4.0/). 